\title{
Dexmedetomidine Promotes Alveolar Fluid Clearance by Upregulating Na,K-ATPase Expression in a Rat Model of Acute Lung Injury via a2 AR/PI3K/Akt Pathway
}

\section{Mingzhu Xia}

Shenzhen Luohu Hospital Group Luohu People's Hospital

Zhi Huang

Shenzhen Luohu Hospital Group Luohu People's Hospital

\section{Mingyu Xu}

Shenzhen People's Hospital

Chao Hai

Shenzhen People's Hospital

\section{Wenbo Diao}

Shenzhen People's Hospital

yuanxu Jiang ( $D$ 13613051840@163.com )

Shenzhen People's Hospital https://orcid.org/0000-0002-7230-3372

\section{Original article}

Keywords: Dexmedetomidine, Acute lung injury, Alveolar fluid clearance, Na, K-ATPase, a2AR, PI3K, Akt

Posted Date: June 1st, 2021

DOl: https://doi.org/10.21203/rs.3.rs-532699/v1

License: (c) (1) This work is licensed under a Creative Commons Attribution 4.0 International License.

Read Full License 


\section{Abstract}

Our previous studies have shown that Dexmedetomidine (Dex), $a_{2}$ adrenergic receptor $\left(a_{2} A R\right)$ agonist, reduces pulmonary edema in LPS-induced acute lung injury (ALI), but the mechanism is not clear. The purpose of this study is to explore whether Dex promotes AFC by upregulating the expression of $\mathrm{Na}, \mathrm{K}$ ATPase in LPS-induced ALI and possible molecular mechanisms. Histology of the lungs was assayed with $\mathrm{H}$-E staining, and the lung injury score was calculated. $\mathrm{PaO}_{2}, \mathrm{PaO}_{2} / \mathrm{FiO}_{2}$, the lung index, wet/dry $(W / D)$ ratio of the lung tissues and alveolar fluid clearance(AFC) was measured; The concentrations of TNF- $a$, IL-1 $\beta$, IL- 6 in bronchoalveolar lavage fluid (BALF) and serum were measured. Myeloperoxidase (MPO) activity in lung tissues were determined. The apoptosis rate of A549 cells and the expression of $\mathrm{Bcl}-2$ and Bax were evaluated. The expression of $\mathrm{Na}, \mathrm{K}-\mathrm{ATPase}, \mathrm{p}-\mathrm{PI} 3 \mathrm{~K}$ and $\mathrm{p}$-Akt in vivo and in vitro were evaluated. Dex significantly alleviated lung tissue injury induced by LPS. Dex treatment reduced the W/D, lung index and MPO activity, increased $\mathrm{PaO}_{2}, \mathrm{PaO}_{2} / \mathrm{FiO}_{2}$ and $\mathrm{AFC}$ in LPS-induced $\mathrm{ALI}$. In addition, Dex reduced the concentrations of TNF- $\alpha$, IL- $\beta$ and IL- 6 in BALF and serum. Dex reduced the apoptosis rate, up-regulated the expression of Bcl-2 and down-regulated the expression of Bax in LPS-stimulated A549 cells. Furthermore, Dex increased the expression of $a_{1} \mathrm{Na}$,K-ATPase, $\beta_{1} \mathrm{Na}$,K-ATPase and p-PI3K , p-Akt in vivo and vitro. However, these effects of Dex were partially reversed by the $a_{2} A R$ inhibitor yohim-

bine or PI3K inhibitor LY294002. Collectively, these results suggest that Dex attenuates pulmonary edema by stimulating AFC via upregulating the Na,K-ATPase expressi-

on in LPS-induced acute lung injury by modulating the $a_{2}$ AR/PI3K/Akt signaling pathway.

\section{Introduction}

Pulmonary edema is the central link in the pathogenesis of acute lung injury (ALI) (Schlapfer et al. 2012).If pulmonary edema cannot be eliminated as soon as possible, it will lead to gas exchange disturbance and progressive hypoxaemia, which eventually results in multiple organ damage. Although the mechanism of pulmonary edema is complex in ALI, it is attribute to the imbalance between the formation and clearance of pulmonary edema fluid. Research has shown that the fluid transport function of alveolar epithelium cells is normal or only slightly impaired, and generally there is no pulmonary edema or only slight pulmonary interstitial edema. Severe alveolar edema is often associated with significantly reduced alveolar fluid clearance (AFC) (Mutlu and Sznajder 2005).

AFC is related to aquaporin (AQP) and sodium ion transport (Zhang et al. 2018). Sodium ions are actively transported into the cell, and then enter the cell stroma under the action of the sodium potassium ATP enzyme (Na,K-ATPase) to form an osmotic gradient. Water is then transferred from the water channel to the pulmonary interstitium, and finally absorbed by lymphatic vessels or capillaries. Therefore, $\mathrm{Na}, \mathrm{K}-$ ATPase plays an important role in alveolar fluid transport (Sznajder et al. 2012).Current research suggests that pulmonary edema may be attributed to the inflammatory response during ALI. Ramia et al. (2010) and Berger et al. (2011) reported that several inflammatory cytokines, including TNF-a and IL-1 $\beta$ 
may impair the function of the alveolar epithelial cells and affect $\mathrm{Na}$,K-ATPase expression. Lan et al. (2017) and Zhuo et al. (2018) demonstrated that inhibiting the release of inflammatory cytokines may promote alveolar fluid clearance (AFC) by increasing the expression of $\mathrm{Na}, \mathrm{K}$-ATPase. Therefore, inhibition of the inflammatory response may be beneficial for upregulating $\mathrm{Na}$,K-ATPase expression and reducing pulmonary edema in LPS-induced ALI.

Dexmedetomidine (DEX), a selective agonist of $a_{2} A R$, has sedative properties, and has been used under general anaesthesia. Zhou et al.(2019)and Zhou et al.(2019) and Liu et al.(2016) reported that Dex has potential anti-inflammatory effects both in vivo and in vitro. In addition, Dex has been shown to alleviate pulmonary edema in ALI (Hancl et al. 2012). Consistent with these studies, our previous study found that Dex could reduce lipopolysaccharide (LPS)-induced pulmonary edema in ALI rats, increase the partial pressure of oxygen, reduce the inflammatory response of lung tissue, and increase the expression of aquaporin 1 and 5 (AQP1, AQP5) in lung tissue (Jiang et al. 2015), suggesting that Dex may alleviate pulmonary edema by promoting AFC through increasing AQP expression. These results prompted us to hypothesize that the effect of Dex on pulmonary edema may be related to the expression of Na,K-ATPase. In addition, the molecular mechanism by which Dex reduces pulmonary edema has not been fully elucidated. Therefore, this study investigated whether Dex regulates the expression of Na,K-ATPase through the a2AR /PI3K/Akt pathway, thereby stimulating AFC and alleviating pulmonary edema.

\section{Material And Methods}

\section{Animals}

Twenty-four 6 to 8 weeks old Wistar rats weighing 220-250g were provided by the Guangdong Medical Animal Experiment Center (China). The rats were housed in an environmentally controlled animal care facility, where they were fed ad libitum, and exposed to 12-h light/dark cycles. The protocol was approved by the Animal Care Committee of the Second Clinical Medical College of Jinan University(Shenzhen, China), and was carried out according to institutional guidelines for animal care and by the Guide for Care and Use of Laboratory Animals published by the United States National Institutes of Health.

\section{Experimental protocol}

The rats were anaesthetized with sodium pentobarbital (50 mg/kg, i.p. injection). The left femoral vein of each rat were punctured with catheters (PE-50) for administration of drugs. A tracheostomy was performed, and a 14-gauge angiocather was inserted as a tracheostomy tube to keep the airway unobstructed. After tracheostomy, anaesthesia was maintained by supplem-

entary injections of pentobarbital (approximately $1-3 \mathrm{mg} / \mathrm{kg}$, i.v.), as required.

The animals were randomly assigned to four groups $(n=6)$ : Control group (Control), ALI model group (LPS group), Dex treatment group (LPS + Dex), and LPS + Dex + yohimbine group (LPS + Dex + YOH). Rats in the Control group were treated with $0.9 \%$ normal saline $(5 \mathrm{ml} / \mathrm{kg}$, i.p.). LPS $(20 \mathrm{mg} / \mathrm{kg}$, i.p. ) was 
administered to induce the ALI model. Rats in the LPS + Dex group received Dex $(100 \mu \mathrm{g} / \mathrm{kg}$, i.p.) immediately after LPS treatment.The Dex dose was determined based on previous studies (Hancl et al. 2012). Rats in the LPS + Dex +YOH group received yohimbine $(0.1 \mathrm{mg} / \mathrm{kg}$, i.p.) $30 \mathrm{~min}$ prior to LPS administration and then received the same treatment as the LPS + Dex group. At the end of the experiment, $1.0 \mathrm{~mL}$ of blood was collected for blood gas analysis. Another sample of blood $(1.5 \mathrm{~mL})$ and the bronchoalveolar lavage fluid (BALF) was collected to measure inflammatory cytokines. All rats were sacrificed by bloodletting. The samples of lung tissues were removed for further examination.

\section{Histological examinations}

After the rats are sacrificed,the lung tissues were taken. The specimens were routinely fixed and embedded in paraffin. Sections were stained with haematoxylin and eosin (H\&E) for light microscopy analysis. The histological lung injury was scored based on the alveolar congestion, haemorrhage, neutrophil infiltration into the airspace or vessel wall, and thickness of the alveolar wall, and the thickness of the alveolar septum in five random fields in a blinded manner using light microscopy. Lung sections were scored as 1 (no or very slight pathological changes), 2 (slight pathological changes), 3 (moderate pathological changes), or 4 (severe pathological changes). Evaluation scores were added to the total injury score.

\section{Measurement of arterial oxygen tension $\left(\mathrm{PaO}_{2}\right)$ and oxygenation index $\left(\mathrm{PaO}_{2} / \mathrm{FiO}_{2}\right)$}

A 1.0-mL blood sample was collected from the right common carotid artery before the rats were sacrificed, and $\mathrm{PaO}_{2}$ was immediately measured with a blood gas analyser (Stat Profile pHOx, Nova Biomedical Corporation; Waltham, MA, USA). $\mathrm{PaO}_{2} / \mathrm{FiO}_{2}$ was calculated according to the concentration of inhaled oxygen.

\section{Measurement of lung index and wet/dry weight ratio (W/D)}

At the end of the experiments, the rats were sacrificed, thoracotomy was performed immediately, and the whole lungs were removed and weighed. The ratio of whole lung wet weight to body weight is the lung index. The upper lobe of the right lung was removed, and the measured weight indicates the wet weight. Then it was placed in an oven at $75^{\circ} \mathrm{C}$, and baked for 24 hours, and the measured weight represented the dry weight, the degree of pulmonary edema was evaluated by calculating the ratio of W/D

\section{Myeloperoxidase (MPO) activity analysis}

The lung tissues were homogenized and centrifuged, and the supernatant was incubated in a water bath $\left(60^{\circ} \mathrm{C}\right)$ for $2 \mathrm{~h}$ for subsequent determination of MPO activity according to the manufacturer's instructions of the assay kits.

\section{Detection of TNF-a, IL-1 $\beta$, IL-6 in BALF and serum}


After the rats were sacrificed, the main bronchus was exposed. The right bronchus was ligated, and a homemade tracheal catheter was inserted into the main bronchus. Then, $2 \mathrm{~mL}$ cold phosphate-buffered saline (PBS) was infused into the left lung and extracted three times. The bronchoalveolar lavage fluid (BALF) was centrifuged at $1200 \times \mathrm{g}$ for $10 \mathrm{~min}$ at $4^{\circ} \mathrm{C}$. The supernatant was separated into aliquots and stored at $-70^{\circ} \mathrm{C}$. An aliquot of BALF supernatant was used to assay the levels of TNF-a, IL-1 $\beta$, IL-6 by ELISA according to the manufacturer's instructions. Blood samples from the common arteries were collected and serum levels of TNF-a, IL-1 $\beta$, IL- 6 were measured by ELISA according to the manufacturer's instructions.

\section{Immunohistochemical analyses}

Lung tissues were fixed in 10区 neutral formaldehyde solution, and paraffin tissue sections were produced. The paraffin sections were then baked overnight in a $60^{\circ} \mathrm{C}$ oven, dewaxed with dimethyl benzene, dehydrated in gradient ethanol solutions, repaired with $500 \mathrm{ml}$ EDTA antigen repair solution, treated with $50 \mu \mathrm{l} 3 \%$ hydrogen peroxide solution at room temperature for $20 \mathrm{~min}$ to block endogenous peroxidase activity and rinsed with TBS 3 times ( 3 min each time). Then, 5\% normal goat serum solution was added at room temperature for $20 \mathrm{~min}$, and the superfluous liquid was discarded without washing. Diluted primary antibody was added, and the tissues were incubated at room temperature for $30 \mathrm{~min}$ and washed with TBS 3 times ( 3 min each time). Secondary antibody (biotinylated goat anti-rabbit lgG) was added, and the tissues were incubated at room temperature for $30 \mathrm{~min}$ and washed with TBS 3 times (3 min each time). After that, the cells were stained with 3,3-diaminobenzidine for $3 \sim 5 \mathrm{~min}$. PBS was used instead of primary antibody for the negative control group. The average optical densities (AODs) of $a_{1} \mathrm{Na}$,KATPase, $\beta_{1} \mathrm{Na}$,KATPase were measured by an imaging analysis system.

\section{Measurement of alveolar fluid clearance}

The AFC was determined by measuring the Evans blue-labeled albumin concentration. First, $5 \%$ bovine serum albumin perfusion solution labeled with Evans blue was injected $(5 \mathrm{ml} / \mathrm{kg})$ into the left lung via the trachea, and $2 \mathrm{ml}$ oxygen was injected to facilitate distribution. The rats were ventilated with $100 \%$ oxygen, and the positive end expiratory pressure was kept at $2 \sim 3 \mathrm{~cm} \mathrm{H}_{2} \mathrm{O}$ during the baseline period to maintain lung tension. These tissue units were wrapped with plastic wrap and then incubated in a $37^{\circ} \mathrm{C}$ water bath for $1 \mathrm{~h}$. The alveolar fluid was immediately aspirated, and labeled albumin was measured by a spectrophotometer at $620 \mathrm{~nm}$. AFC was calculated based on the following formula: AFC $(\%)=\left[\left(C_{f}-C_{i}\right) /\right.$ $\left.\mathrm{C}_{f}\right] \times 100 \otimes$, where Ci represents the concentration of injected Evans blue-labeled $5 \%$ albumin and $\mathrm{C}_{f}$ represents the final concentration of Evans blue-labeled $5 \%$ albumin.

\section{Cell culture and treatment}

A549 cells (Cell Bank of the Chinese Academy of Sciences, Shanghai, China) were seeded in culture dishes at a density of $1 \times 10^{6}$ cells $/ \mathrm{cm}^{2}$ and cultured in a $5 \% \mathrm{CO}_{2}$ and $95 \%$ air atmosphere in Dulbecco's modified Eagle medium (DMEM) with $10 \%$ fetal bovine serum, $0.1 \mathrm{mg} / \mathrm{ml}$ streptomycin, and $100 \mathrm{U} / \mathrm{ml}$ penicillin. The culture medium was changed every two days. For all experiments, the cells were subcultured in six-well plates. Once the cells reached $80 \%$ confluence, they were serum-starved for $24 \mathrm{~h}$. 
Following starvation, the cells were treated with LPS $(1 \mu \mathrm{g} / \mathrm{ml})$ in the presence or absense of Dex $(10 \mu \mathrm{M})$. Yohimbine $(100 \mu \mathrm{M})$, an $\mathrm{a}_{2} \mathrm{AR}$ inhibitor, was used 1 hours prior to Dex administration. LY294002, a PI3K inhibitor, was used at a concentration of $(10 \mu \mathrm{M}) 30 \mathrm{~min}$ prior to LPS $(1 \mu \mathrm{g} / \mathrm{ml})$ administration.

\section{Cell viability assay}

The CCK8 assay was performed to measure cell viability. The cells $(100 \mu \mathrm{l} /$ well) were cultured in a 96 -well plate for $24 \mathrm{~h}$. Then, $10 \mu \mathrm{l} \mathrm{CCK8}$ solution was added to each well, the culture plate was incubated in the incubator for $2 \mathrm{~h}$ under $5 \% \mathrm{CO} 2$ at $37^{\circ} \mathrm{C}$, and the absorbance at $490 \mathrm{~nm}$ was measured with a microplate reader.

\section{LDH activity assay}

The cells $(100 \mu \mathrm{l} /$ well) were cultured in a 96 -well plate for $24 \mathrm{~h}$. The supernatant was collected to measure lactate dehydrogenase (LDH) activity by using an LDH assay kit according to the manufacturer's instructions. The absorbance at $490 \mathrm{~nm}$ was measured with a microplate reader.

\section{Hoechst 33258 staining}

The A549 cell suspension was added at a density of $1 \times 10^{5}$ cells/well into 6-well plates. A549 cells were treated with PBS, LPS $(1 \mu \mathrm{g} / \mathrm{ml})$, LPS + Dex $(10 \mu \mathrm{M})$, LPS + Dex + Yohimbime $(100 \mu \mathrm{M})$. After $24 \mathrm{~h}$, cells were washed twice with TBST and fixed with $4 \%$ formaldehyde for 10 min at room temperature. Then, four groups of cells were stained with Hoechst 33258 for 30 min at $37^{\circ} \mathrm{C}$. Cell damage was observed under a fluorescence microscope.

\section{Western blot analysis in vivo and vitro}

Proteins were obtained with RIPA lysis buffer (50 mM Tris [pH 7.4], $150 \mathrm{mM} \mathrm{NaCl}, 1 \%$ Triton X-100, $1 \%$ sodium deoxycholate, $0.1 \%$ SDS, sodium orthovanadate, sodium fluoride, EDTA, and leupeptin) and PMSF. The protein concentrations of the supernatants were determined by using a BCA protein assay kit. The proteins were separated by sodium dodecyl sulfate-polyacrylamide gel electrophoresis (SDS-PAGE) and transferred to PVDF membranes. Tris buffer solution containing $5 \%$ skim milk powder was used to block the membrane for $1 \mathrm{~h}$ at room temperature. The membrane was permeabilized with PBS containing $0.05 \%$ Tween 20 and washed with PBST 5 times ( 5 min each time). Then, the membrane was incubated overnight at $4^{\circ} \mathrm{C}$ with the following primary antibodies: $a_{1} N a, K A T P a s e, \beta_{1} N a$,KATPase, p-PI3K,p-AKT and $\beta$-actin.The membrane was incubated with a horseradish peroxidase (HRP)-labeled goat anti-rabbit antibody at room temperature for $3 \mathrm{~h}$, and the membrane was washed with PBST 5 times (5 min each time). Finally, the bands were visualized using an enhanced chemiluminescence kit (ECL) with a UVP gel imaging system. The band intensities were analyzed with Image $\mathrm{J}$ software.

\section{Statistical analysis}

All data are expressed as the mean \pm standard deviation (SD). The significance of the differences among the four groups was tested using one-way ANOVA, and Dunnett's test was used for multiple comparison.A two-side $p$ value less than 0.05 was considered statistically significant. 


\section{Results}

\section{Effects of Dex on acute lung injury induced by LPS}

Firstly, HE staining was performed to observe LPS-induced pathological pulmonary changes.In the Control group, the lung structure was intact, and the alveolar cavity was clear and free from inflammatory cell infiltration. Compared with Control group, LPS induced significant changes in lung injury, namely, interstitial edema, alveolar septum thickening, and a large amount of inflammatory cell infiltration, as evidenced by an increase in the lung injury score. Dex treatment significantly alleviated but yohimbine aggravated the pathological alterations and lung injury scores induced by LPS (Fig. 1a-b, P< 0.01 ). Subsequently, arterial blood samples were obtained for blood gas analysis and showed that $\mathrm{PaO}_{2}$ and $\mathrm{PaO}_{2} / \mathrm{FiO}_{2}$ was significantly lower in the LPS group than in the control group. Dex treatment significantly increased but yohimbine decreased the $\mathrm{PaO}_{2}$ and $\mathrm{PaO}_{2} / \mathrm{FiO}_{2}$ (Fig. $1 \mathrm{c}-\mathrm{d}, \mathrm{P}<0.01$ or 0.05 ). In addition, the degree of pulmonary edema and lung tissue MPO activity were performed to further assess the lung injury. W/D, lung index, MPO activity in the LPS group were increased compared with control group, Dex treatment significantly increased but yohimbine decreased the W/D, lung index, MPO activity (Fig. 1e-g, P $<0.01$ or 0.05 ) .

\section{Effects of Dex on Alveolar fluid clearance(AFC)}

Compared with control group, AFC was decreased in LPS group. Compared with LPS group, AFC was increased in LPS + Dex group,while $a_{2} A R$ inhibitor yohimbine reversed the effect of Dex (Fig. 2, $p<0.01$ ).

\section{Effects of Dex on the concentrations of TNF- $a, I L-\beta$, IL- 6 in BALF and serum}

Compared with control group, the concentration of TNF-a, IL- $\beta$ and IL- 6 were increased in BALF and serum in LPS group. Compared with LPS group, the concentration of TNF-a, IL- $\beta$ and IL- 6 were decreased in BALF and serum in LPS + Dex group, while $a_{2} A R$ inhibitor yohimbine reversed the effect of Dex (Fig. 3a$f, P<0.01)$.

\section{Effects of Dex on $\alpha_{1} \mathrm{Na}$,KATPase and $\beta_{1} \mathrm{Na}$,KATPase expression in vivo}

Immunohistochemical analysis was used to determine the expression of $\mathrm{a}_{1} \mathrm{Na}$,KATPase and $\beta_{1} \mathrm{Na}$,KATPase. Immunostained cells appeared brown. The expression of $\mathrm{a}_{1} \mathrm{Na}$,KATPase and $\beta_{1} \mathrm{Na}$,KATPase were decreased in the LPS group compared with the control group, but were increased in the LPS + Dex group compared with the LPS group, while $a_{2} A R$ inhibitor yohimbine reversed the effect of Dex (Fig. 4a-d, $P<0.01$ ). 
To further confirm that Dex stimulates AFC by increasing the expression of Na,KATPase, the expression levels of $a_{1} \mathrm{Na}$,KATPase and $\beta_{1} \mathrm{Na}$,KATPase in lung tissues were detected by western blotting. Compared with Control group, the expression of $a_{1} \mathrm{Na}$,KATPase and $\beta_{1} \mathrm{Na}$,KATPase were decreased in LPS group. Compared with LPS group, the expression of $a_{1} \mathrm{Na}$,KATPase and $\beta_{1} \mathrm{Na}$,KATPase were increased in LPS + Dex group, while $a_{2} A R$ inhibitor yohimbine reversed the effect of Dex (Fig. 4e-f, $p<0.01$ ).

\section{Dex attenuated LPS-induced A549 cell injury}

Different concentrations of dexmedetomidine alone did not affect cell viability (Fig. 5a, $p>0.05$ ). Compared with the control group, LPS expoure reduced the cell viabilitiy and increased the LDH release, which was alleviated by $0.1-100 \mu \mathrm{m}$ Dex treatment. The use of $10 \mu \mathrm{m}$ and $100 \mu \mathrm{m}$ Dex had the best therapeutic effect (Fig. 5b-c, $p<0.05$ or 0.01$)$. Therefore, Dex $(10 \mu \mathrm{m})$ was used in subsequent cell experiments.

\section{Dex inhibits LPS-induced A549 cell apoptosis}

The Hoechst staining results showed that LPS expoure increased the apoptosis rate, which was decreased by Dex treatment. Howere, $a_{2}$ AR inhibitor yohimbine reversed the effect of Dex. (Fig. 6a-b, $p<$ 0.01 ). To further confirm the protective effects of Dex, the expression of Bax, Bcl-2 in the lung were evaluated by western blotting. We found that the expression of Bax increased and the expression of Bcl-2 decreased in LPS group, which was alleviated by Dex treatment. Howere, $a_{2} A R$ inhibitor yohimbine reversed the effect of Dex. (Fig. 6c-e, p $<0.01$ ).

\section{Effects of Dex on $\alpha_{1} \mathrm{Na}, \mathrm{KATPase}$ and $\boldsymbol{\beta}_{1} \mathrm{Na}, \mathrm{KATPase}$ expression in vitro}

To further confirm that Dex stimulates AFC by increasing the expression of Na,KATPase, we detected the expression levels of $\mathrm{a}_{1} \mathrm{Na}$,KATPase and $\beta_{1} \mathrm{Na}$,KATPase in A549 cells.Compared with Control group, the expression of $a_{1} \mathrm{Na}$,KATPase and $\beta_{1} \mathrm{Na}$,KATPase were decreased in LPS group. Compared with LPS group, the expression of $a_{1} \mathrm{Na}$,KATPase and $\beta_{1} \mathrm{Na}$,KATPase were increased in LPS + Dex group, while $a_{2} A R$ inhibitor yohimbine reversed the effect of Dex (Fig. 7a-C, $p<0.01$ ).

\section{Effects of Dex on p-PI3K and p-Akt expression in vivo and vitro}

Compared with control group, the expression of p-PI3K and p-Akt was decreased in LPS group in vivo. Compared with LPS group, the expression of p-PI3K and p-Akt was increased in LPS + Dex groupin in vivo, while $a_{2} A R$ inhibitor yohimbine reversed the effect of Dex (Fig. 8a - c, $p<0.01$ ).

To further confirm that whether Dex regulates the expression of Na,KATPase through the $a_{2}$ AR/PI3K/Akt signaling pathway. we administered PI3K inhibitors LY294002 as well as $a_{2}$ AR inhibitors yohimibine in 
LPS-stimulated A549 cell to observe the expression of p-PI3K

and p-Akt. Compared with the control group, the expression of p-PI3K and p-Akt was decreased in LPS group in vitro. Compared with LPS group, the expression of p-PI3K and p-Akt was increased in LPS + Dex group in vitro, while $a_{2} A R$ inhibitor yohimbine and PI3K inhibitor LY294002 reversed the effect of Dex $(p<$ $0.01)($ Fig. $9 a-c, p<0.01$ ).

\section{Discussion}

Our data clearly indicated that lung index and W/D ratio were significantly increased in LPS-induced ALI, while Dex reduced the lung index and W/D ratio, indicating that Dex alleviated pulmonary edema in LPSinduced $\mathrm{ALI}$ in rats.Consistent with the results, Dex significantly increased $\mathrm{PaO}_{2}, \mathrm{PaO}_{2} / \mathrm{FiO}_{2}$ and improved lung histopathological changes. In addition, Dex treatment promotes AFC following LPS exposure, it seems possible that Dex reduces pulmonary edema by increasing $\mathrm{AFC}$, which in turn increases $\mathrm{PaO}_{2}$. Our study also observed that Dex inhibited the down-regulation of Na,K-ATPase expression induced by LPS. So, it is likely that Dex reduce pulmonary edema by promoting AFC through the elevation of the $\mathrm{Na}, \mathrm{K}-$ ATPase expression. Howere, these effects of Dex were partially reversed by $a_{2} A R$ inhibitor yohimbine, indicating that Dex acts through the $a_{2} A R$. Furthermore, our study demonstrated that Dex increased the expression of P-PI3K and p-Akt, while $\mathrm{a}_{2} A R$ inhibitor yohimbine partially reversed the effect of Dex, indicating that Dex reduced pulmonary edema through increasing $\mathrm{Na}$,K-ATPase expression by $a_{2} A R / P I 3 K / A k t$ signaling pathway.

Although aquaporin (AQP) is important in water transport between alveolar cavity and capillaries, but the driving force for water transport is the osmotic gradient formed by $\mathrm{Na}^{+}$transmembrane transport (Matthay et al. 1996). Sodium ions are actively transported into alveolar epithelial cells, it then enters the alveolar stroma in the presence of $\mathrm{Na}$, K-ATpase, forming an osmotic gradient, water is then transferred from the water channel to the pulmonary interstitial, and finally absorbed back by lymphatic vessels or capillaries. In this process, the function of Na,K-ATPase is to transport three sodium ions out of the cell and pump two potassium ions at the same time, thus forming the permeability gradient difference between inside and outside the cell membrane. The increased expression or activity of Na,K-ATPase on the alveolar epithelial cell membrane can promote alveolar fluid clearance (Smith et al. 2013). On the contrary, Vadasz et al. (2014) and Wang et al. (2013) and Peteranderl et al. (2016) reported that the low expression of $\mathrm{Na}$,K-ATPase on the alveolar epithelial cell membrane or inhibition of its activity leads to a decrease in alveolar fluid clearance. Huang et al.(2014) and Wang et al.(2014) and Emr et al. (2015) found that the expression of $\mathrm{Na}, \mathrm{K}-\mathrm{ATP}$ ase and AFC were decreased during the ALI, suggesting that inhibiting the decrease of $\mathrm{Na}, \mathrm{K}-\mathrm{ATP}$ ase expression is a new way to promote AFC and alleviate pulmonary edema in ALI. In the previous study, we found that Dex alleviated pulmonary edema through up-regulating the expression of AQP (Jiang et al. 2015), but it is not clear whether its effect is related to increase the $\mathrm{Na}$,K-ATPase expression. In this study, we observed that the expression of the $\mathrm{a}_{1} \mathrm{Na}$, K-ATPase and $\beta_{1} \mathrm{Na}, \mathrm{K}$ ATPase expression were decreased in LPS group,while Dex treatment enhanced the expression of the 
$\mathrm{a}_{1} \mathrm{Na}, \mathrm{K}-\mathrm{ATP}$ ase and $\beta_{1} \mathrm{Na}, \mathrm{K}-\mathrm{ATP}$ ase in the lung tissues and alveolar epithelial cells. In addition, immunohiso-

chemical analysis of lung tissue confirmed similar results. Moreover, this effect of Dex appears to occur through $a a_{2} A R$. These findings suggest that Dex promotes AFC and reduces pulmonary edema by increasing $\mathrm{a}_{1} \mathrm{Na}$,K-ATPase and $\beta_{1} \mathrm{Na}$,K-ATPase expression.

The exact mechanism behind ALI remains unclear, but excessive inflammatory response is mainly responsible for the development of ALI. Studies have shown that inflammatory cytokines such as TNF- $a$, IL-1 $\beta$ and IL- 6 can inhibit the expression of Na,K-ATPase (Song et al.2016). Our study found that LPS induced the increase of pro-inflammatory cytokines TNF- $\alpha$, IL-1 $\beta$ and IL-6, suggesting that inflammatory response may be an important reason for the decreased expression of $\mathrm{Na}, \mathrm{K}$-ATPase in this study. Liu et al. (2016) and Tasdogan et al.(2008) and Peng et al.(2013) demonstrated that Dex has an antiinflammatory effect through inhibiting inflammatory cytokines such as TNF-a, IL-1ß. In addition, Xu et al. (2015) and Gu et al.(2011) reported that Dex reduced pulmonary edema in ALI. Our study found that Dex decreased the concentration of TNF- $a$, IL-1 $\beta$ and IL- 6 in BALF and serum and reduced neutrophil infiltration in lung tissue, suggesting that Dex may increase the Na,K-ATPase expression to stimulate AFC and alleviate pulmonary edema through inhibiting inflammatory response in the LPS-induced ALI in rats.

Apoptosis plays an important role in the pathogenesis of ALI(Zheng et al. 2020). Na,K-ATPase were expressed in alveolar epithelial cells. So, Apoptosis of alveolar epithelial cells may decrease the expression of Na,K-ATPase. Sun et al.(2019) improved that Dex inhibited the apoptosis of alveolar epithelial cells.Consistent with these studies, our study found that Dex significantly reduced LPS-induced alveolar epithelial cell apoptosis, while $\mathrm{a}_{2} \mathrm{AR}$ inhibitors yohimbine partially reversed the effect of Dex, suggesting that the effect of DEX on apoptosis was $\mathrm{a}_{2} \mathrm{AR}$ dependent. Bax and $\mathrm{Bcl}-2$ play important roles in the regulation of apoptosis. High expressionof Bax (apoptosis-promoting) and low expression of $\mathrm{Bcl}-2$ (anti-apoptosis) can result in apoptosis. In the present study, we found that Dex upregulated the expression of $\mathrm{Bcl}-2$ and inhibited the expression of $B a x$, and $a_{2} A R$ inhibitors yohimbine partially reversed the effect of Dex, indicating that Dex acted in an $a_{2} A R$-dependent manner.These results suggest that that Dex increases $\mathrm{Na}$,K-ATPase expression by reducing the apoptosis of alveolar epithelial cells as well as inhibiting inflammatory response.

Our study confirmed that Dex alleviated pulmonary edema by up-regulating the expression of $\mathrm{Na}, \mathrm{K}$ ATPase, but the molecular mechanism was not clear. The lipid kinase PI3K generates phosphatidylinositol $(3,4,5)$-trisphosphate (PIP3), which is a second messenger that facilitates the translocation of Akt to the plasma membrane. At the membrane, Akt is phosphorylated and plays an important role in processes such as cell proliferation, differentiation, survival and apoptosis. Li et al. (2018) and Sun et al.(2019) reported that Dex has a protective effect on LPS or renal ischemiareperfusion induced alveolar epithelial cells and pulmonary microvascular endothelial cells by the activation of a2AR/PI3K / Akt pathway. Our previous studies have shown that Dex reduces pulmonary edema by activating the PI3K/Akt /Nedd4-2 pathway(Jiang et al. 2021). In addition, the increased 
expression of Na,K-ATPase is related to the activation of PI3K/Akt pathway (Bhargava et al. 2007). Therefore, it seems likely that Dex has a protective effect on LPS-induced ALI through activating PI3K/Akt pathway by stimulating $a_{2} A R$. Our studies found that LPS inhibited the expression of p-PI3K and p-Akt, but Dex significantly increased the expression of $\mathrm{p}$-PI3K and p-Akt, while $\mathrm{a}_{2} \mathrm{AR}$ inhibitor yohimbine partially reversed the effect of Dex. In vitro, We found that LY294002 (PI3K inhibitor) decreased the expression of $p$-PI3K and $p$-Akt as well as $a_{2} A R$ inhibitor yohimbine. These results furtherly suggest that Dex may enhance the Na,K-ATPase expression through $\mathrm{a}_{2}$ AR-mediated activation of PI3K/Akt, and contribute to stimulate AFC to decrease lung edema.

In conclusion, Dex promotes AFC and attenuates pulmonary edema by up-regulating the expression of $\mathrm{Na}, \mathrm{K}-\mathrm{ATP}$ ase in LPS induced ALI, which may be related to $\mathrm{a}_{2} \mathrm{AR} / \mathrm{PI} \mathrm{KK} / \mathrm{Akt}$ signaling pathway. Our results provide new insight into alleviating pulmonary edema in LPS-

induced ALI and suggest a new therapeutic use for Dex in patients with ALI.

\section{Declarations}

\section{Acknowledgments}

The authors acknowledge the help of Xu-Jing doctor in the pathological examination of the tissue.

\section{Authors'contributions}

YJ and MX worked on the experimental design. JX performed the histological and immunohistochemistry examination of the lung. $\mathrm{MX}, \mathrm{ZH}, \mathrm{MX}, \mathrm{CH}, \mathrm{WD}$ and $\mathrm{YJ}$ conducted the experiments, analyzed the data, and interpreted the data. All authors read and approved the final manuscript.

\section{Funding}

This study was funded by the Scientific Research Project of Shenzhen Health and Family Planning System (SZFZ2018032) and by Shenzhen Key Medical Discipline Construction Fund (No.SZXK044) and Sanming Project of Medicine in Shenzhen (SZSM202011021).

\section{Availability of data and materials}

The supporting data for present fndings is under ethics restrictions and is hence not presented here.

\section{Ethics approval and consent to participate}

All the animal experiments were approved by ethics committee of Shenzhen People's Hospital, Shenzhen, Guangdong Province, 518002, China. 


\section{Consent for publication}

Not applicable.

\section{Competing interests}

The authors declare no competing interests

\section{Author details}

${ }^{1}$ Hubei Community Health Service Management Center, Shenzhen Luohu Hospital Group Luohu People's Hospital, Shenzhen, China. ${ }^{2}$ Department of Anesthesiology, Shenzhen People's Hospital (The Second Clinical Medical College, Jinan University;The Fist Affiliated Hospital,Southern University of Science and Technology), Shenzhen,China.

\section{References}

Berger G, Guetta J, Klorin G, Badarneh R, Braun E, Brod V, Saleh NA, Katz A, Bitterman H囚2011). Sepsis impairs alveolar epithelial function by downregulating Na-KATPase pump.

Am J Physiol Lung Cell Mol Physiol 301: L23-L30.

Bhargava M, Lei J, Mariash CN, Ingbar DH(2007). Thyroid hormone rapidly stimulates alveolar $\mathrm{Na}, \mathrm{K}-$ ATPase by activation of phosphatidylinositol 3-kinase. Curr Opin Endocrin-

ol Diabetes Obes 14(5):416-420

Emr BM, Roy S, Kollisch-Singule M, Gatto LA, Barravecchia M, Lin X, Young JL, Wang G, Liu J (2015). Electroporation-mediated gene delivery of $\mathrm{Na}^{+}, \mathrm{K}^{+}$- ATPase, and ENaC subunits to the lung attenuates acute respiratory distress syndrome in a two-hit porcine model. Shock 43(1):16-23.

Gu J, Chen J, Xia P, Tao G, Zhao H, Ma D (2011). Dexmedetomidine attenuates remote lung injury induced by renal ischemia-reperfusion in mice. Acta Anaesthesiol Scand 55(10):1272-127.

Hancl V,Yurdakan G,Yurtlu S,Turan IÖ, Sipahi EY(2012). Protective effect of dexmedetomi-

dine in a rat model of a-naphthylthiourea -induced acute lung injury. J Surg Res 178 (1):424-430.

Huang B, Wang DX, Deng W(2014,). Protective effects of dexamethasone on early acute lung injury induced by oleic acid in rats. Int J Clin Exp Med 7(12)ه4698 -4709.

Ibacache M, Sanchez G, Pedrozo Z, Galvez F, Humeres C, Echevarria G, Duaso J, Hassi M, Garcia L(2012). Dexmedetomidine preconditioning activates pro-survival kinases and attenuates regional ischemia/ reperfusion injury in rat heart. Biochim Biophys Acta 1822(4): $537-545$. 
Jiang YX. Dai ZL, Zhang XP, Zhao W, Huang Q, Gao LK(2015). Dexmedetomidine alleviates pulmonary edema by upregulating AQP1 and AQP5 expression in rats with acute lung injury induced by lipopolysaccharide. J Huazhong Univ Sci Technolog Med Sci 35(5)®684-688.

Jiang Y, Xia M, Xu J, Huang Q, Dai Z, Zhang X(2021). Dexmedetomidine alleviates pulmon-

ary edema through the epithelial sodium channel $(\mathrm{ENaC})$ via the PI3K/Akt/Nedd4-2 pathway in LPSinduced acute lung injury. Immunol Res.

Lan CC, Peng CK, Tang SE, Huang KL,Wu CP(2017). Carbonic anhydrase inhibitor attenuates ischemiareperfusion induced acute lung injury. PLoS ONE 12(6):e0179822.

Liu Z, Wang Y, Wang Y, Ning Q, Zhang Y, Gong C, Zhao W, Jing G, Wang Q(2016). Dexmedetomidine attenuates inflammatory reaction in the lung tissues of septic mice by activating cholinergic antiinflammatory pathway. Int Immunopharmacol 2016;35:210-

216.

Li J, Chen Q, He X, Alam A, Ning J, Yi B, Lu K, Gu J(2018). Dexmedetomidine attenuates lung apoptosis induced by renal ischemia-reperfusion injury through $a_{2} A R / P I 3 K / A k t$ pathway.J Transl Med 16(1):78

Mutlu GM, Sznajder JI(2005). Mechanisms of pulmonary edema clearance. Am J Physiol Lung Cell Mol Physiol 289(5)『L685-L695.

Matthay M A, Folkesson HG,Verkman AS(1996). Salt and water transport across alveolar and distal airway epithelia in the adult lung. Am J Physiol 270(4Pt 1)凶L487 -L503.

Peteranderl C, Morales-Nebreda L, Selvakumar B, Lecuona E, Vadász I, Morty RE, Schmoldt C (2016).Macrophage-epithelial paracrine crosstalk inhibits lung edema clearance during influenza infection. J Clin Invest 126(4):1566 -1580.

Peng M, Wang YL, Wang CY, Chen C(2013). Dexmedetomidine attenuates lipopolysacchari-

de-induced proinflammatory response in primary microglia. J Surg Res 179(1):e219-225.

Ramia N, Kreydiyyeh SI(2010). TNF-alpha reduces the $\mathrm{Na}^{+} / \mathrm{K}^{+}$ATPase activity in LLC-cells by activating caspases and JNK and inhibiting NF-kappaB. Cell Biol Int 34(6) \607-613.

SchlapferM. Leutert AC, Voigtsberger S, Lachmann RA, Booy C, Beck-Schimmer B (2012). Sevoflurane reduces severity of acute lung injury possibly by impairing formation of alveolar oedema. Clin Exp Immunol 168(1)凶125-134.

Sznajder JI, Factor P, Ingbar DH(2002). Invited review: lung edema clearance: role of $\mathrm{Na}(+)-\mathrm{K}(+)$ - ATPase. J Appl Physiol 93(5):1860-1866. 
Song TT, Bi YH, Gao YQ, Huang R, Hao K, Xu G, Tang JW, Ma ZQ, Kong FP, Coote JH, Chen XQ (2016). Systemic pro-inflammatory response facilitates the development of cerebral edema during short hypoxia. J Neuroinflammation 13(1): 63 .

Smith LS, Zimmerman JJ, Martin TR(2013). Mechanisms of acute respiratory distress syndrome in children and adults: a review and suggestions for future research. Pediatr Crit Care Med 14(6) $\llbracket 631-643$.

Sun J, Zheng S, Yang N, Chen B, He G, Zhu T(2019). Dexmedetomidine inhibits apoptosis and expression of COX-2 induced by lipopolysaccharide in primary human alveolar epithelial type 2 cells.Biochem Biophys Res Commun 517(1):89-95.

Tasdogan M, Kurita A,Kobayashi K, Yamamoto K, Inaba H(2008). Dose and time related effects of dexmedetomidine on mortality and inflammatory responses to endotoxin- induced shock in rats. J Anesth 22(3): 221-228.

Vadasz I, Raviv S, Sznajder JI(2007). Alveolar epithelium and Na,K-ATPase in acute lung injury. Intensive Care Med 33(7): 1243 -1251.

Wang Q, Lian QQ, Li R, Ying BY, He Q, Chen F, Zheng X, Yang Y, Wu DR, Zheng SX, Huang CJ (2013). Lipoxin $\mathrm{A}(4)$ activates alveolar epithelial sodium channel, $\mathrm{Na}, \mathrm{K}$ -

ATPase, and increase alveolar fluid clearance. Am J Respir Cell Mol Biol 48(5)『610-618.

Wang Q, Zheng X, Cheng Y, Zhang YL, Wen HX, Tao Z, Li H, Hao Y, Gao Y, Yang LM(2014). Resolvin D1 stimulates alveolar fluid clearance through alveolar epithelial sodium channel, Na,K-ATPase via ALX/CAMP/PI3K pathway in lipoposaccharide -induced acute lung injury. J Immunol192 (8):3765-3777.

Xu Y, Zhang R, Li C, Yin X, Lv C, Wang Y, Zhao W, Zhang X(2015). Dexmedetomidine attenuates acute lung injury induced by lipopolysaccharide in mouse through inhibition of MAPK pathway. Fundam Clin Pharmacol 29(5): 462-471.

Zhang J, Yan M, Gu W, Chen A, Liu J, Li L, Zhang S, Liu G(2018). Downregulation of aquaporins (AQP1 and AQP5) and Na,K-ATPase in porcine reproductive and respiratory syndrome virus - infected pig lungs. Inflammation 41(3):1104-1114 .

Zhuo XJ, Hao Y, Cao F, Yan SF, Li H, Wang Q, Cheng BH, Ying BY, Smith FG, Jin SW(2018). Protectin DX increases alveolar fluid clearance in rats with lipopolysacchari-

de-induced acute lung injury. Exp Mol Med 50(4):1-13.

Zhou XY, Liu J, Xu ZP, Fu Q, Wang PQ, Zhang HZ(2019). Dexmedetomidine inhibits the lipopolysaccharide-stimulated inflammatory response in microglia through the pathway involving TLR4 and NF-KB. Kaohsiung J Med Sci 35(12):750-756. 
Zhou H, Zhou D, Lu J, Wu C, Zhu Z(2019). Effects of pre-cardiopulmonary bypass administration of dexmedetomidine on cardiac injuries and the inflammatory response in valve replacement surgery with a sevoflurane postconditioning Protocol: A Pilot Study. J. Cardiovasc. Pharmacol 74(2):91-97.

Zheng S, Yang J, Hu X, Li M, Wang Q, Dancer RCA, Parekh D, Gao-Smith F, Thickett DR, Jin S (2020).Vitamin D attenuates lung injury via stimulating epithelial repair, reducing epithelial cell apoptosis and inhibits TGF- $\beta$ induced epithelial to mesenchymal transition. Biochem Pharmacol 177囚 113955

\section{Figures}


a

Control

LPS

LPS+Dex

LPS+Dex+YOH
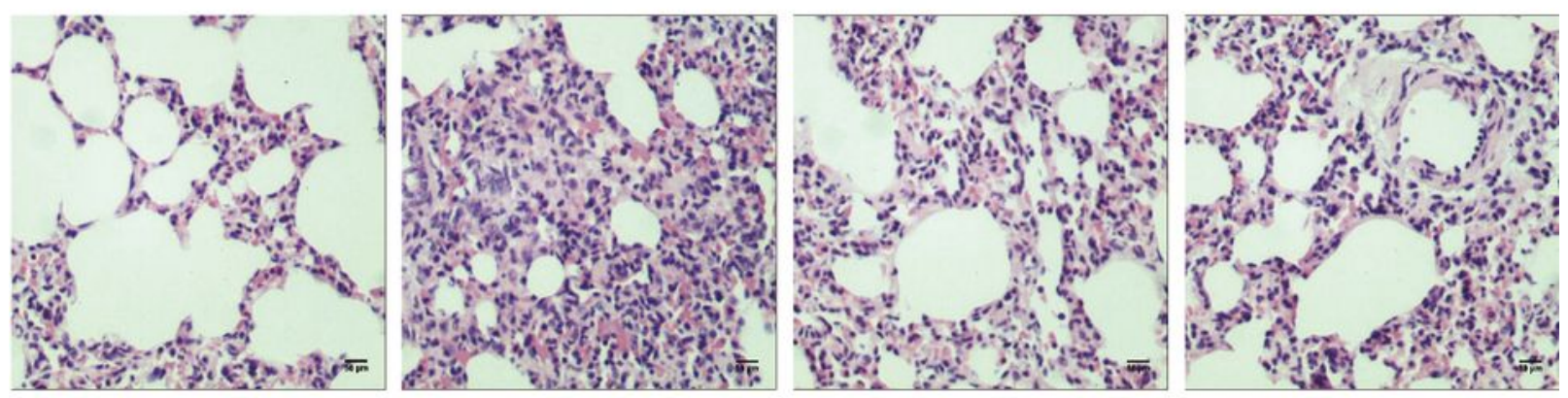

b

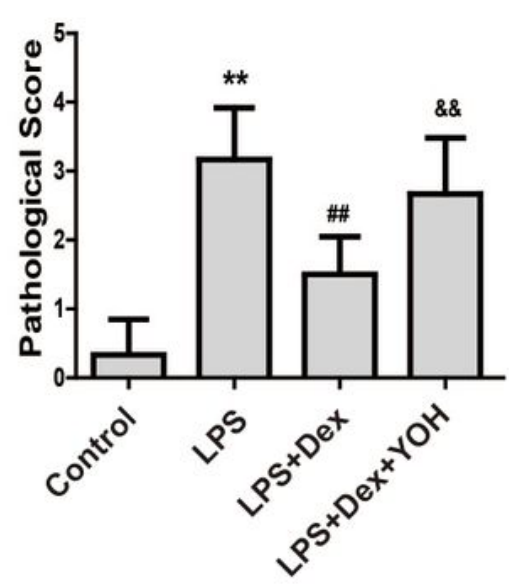

e

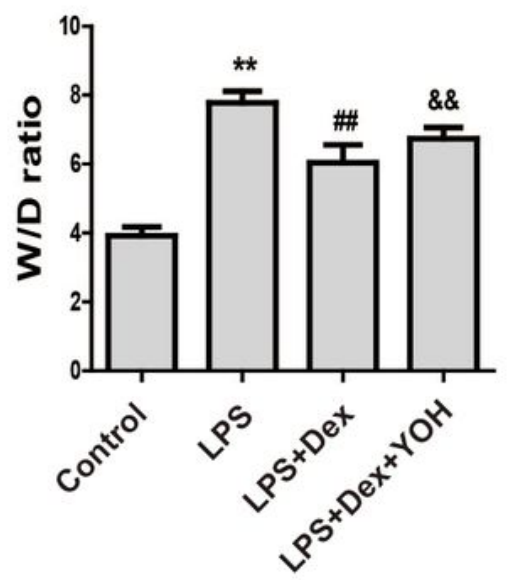

C

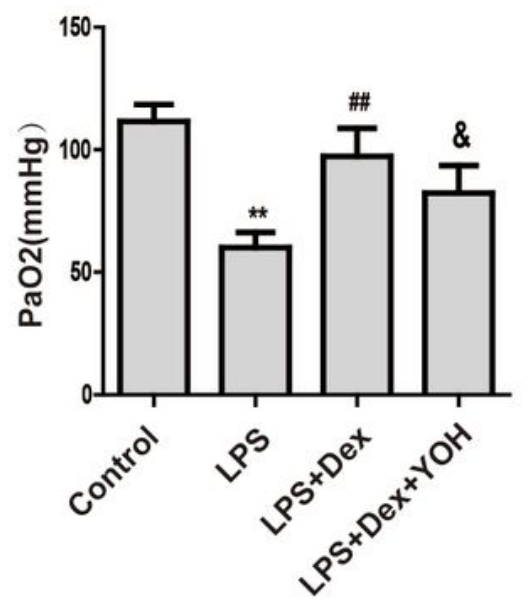

f

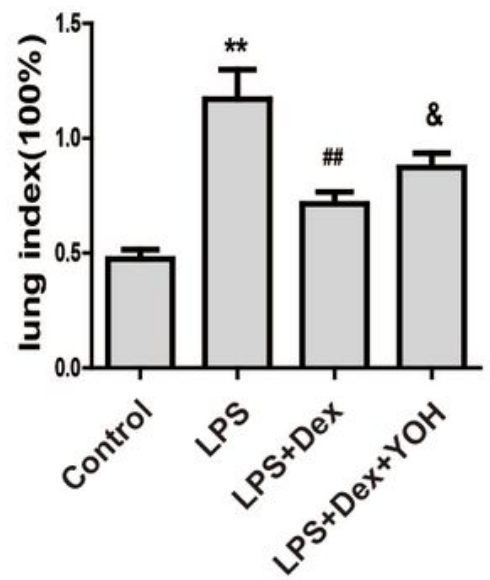

d

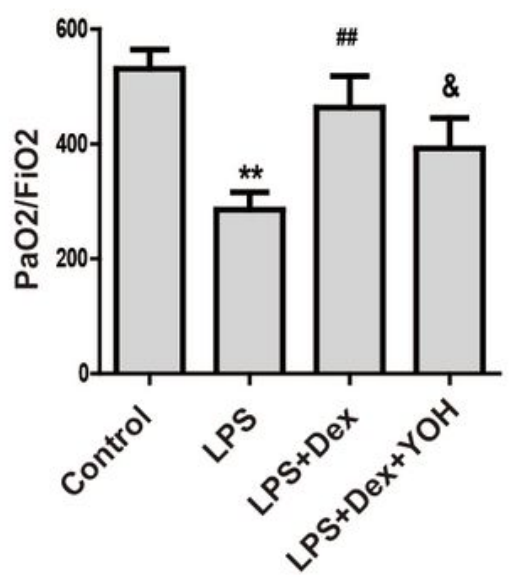

g

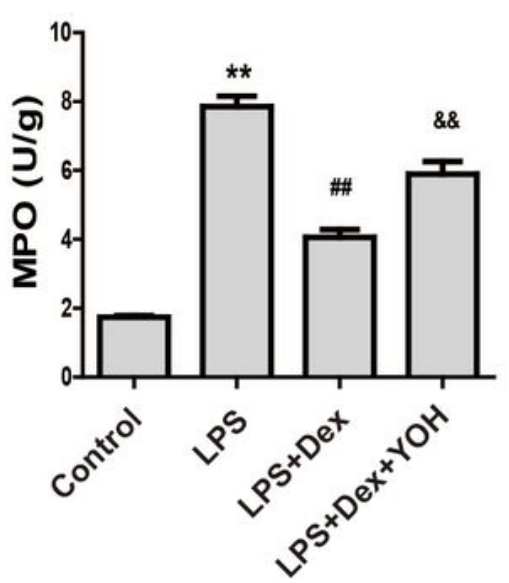

Figure 1

Dex ameliorates LPS-induced ALI in rats. Represents histopathological images of lung tissues(a), histological injury scores for lung tissues (b), the PaO2(c), the PaO2/FiO2(d), the W/D (e), the lung index $(\mathrm{f})$, the MPO of lung tissues $(\mathrm{g})$. All data are expressed as mean \pm standard deviation $(\mathrm{n}=6)$. ${ }^{* \star} \mathrm{P}<0.01 \mathrm{vs}$. the control group; \#\#P<0.01 vs. the LPS group; \&\&P<0.01 vs. the LPS+Dex group. 


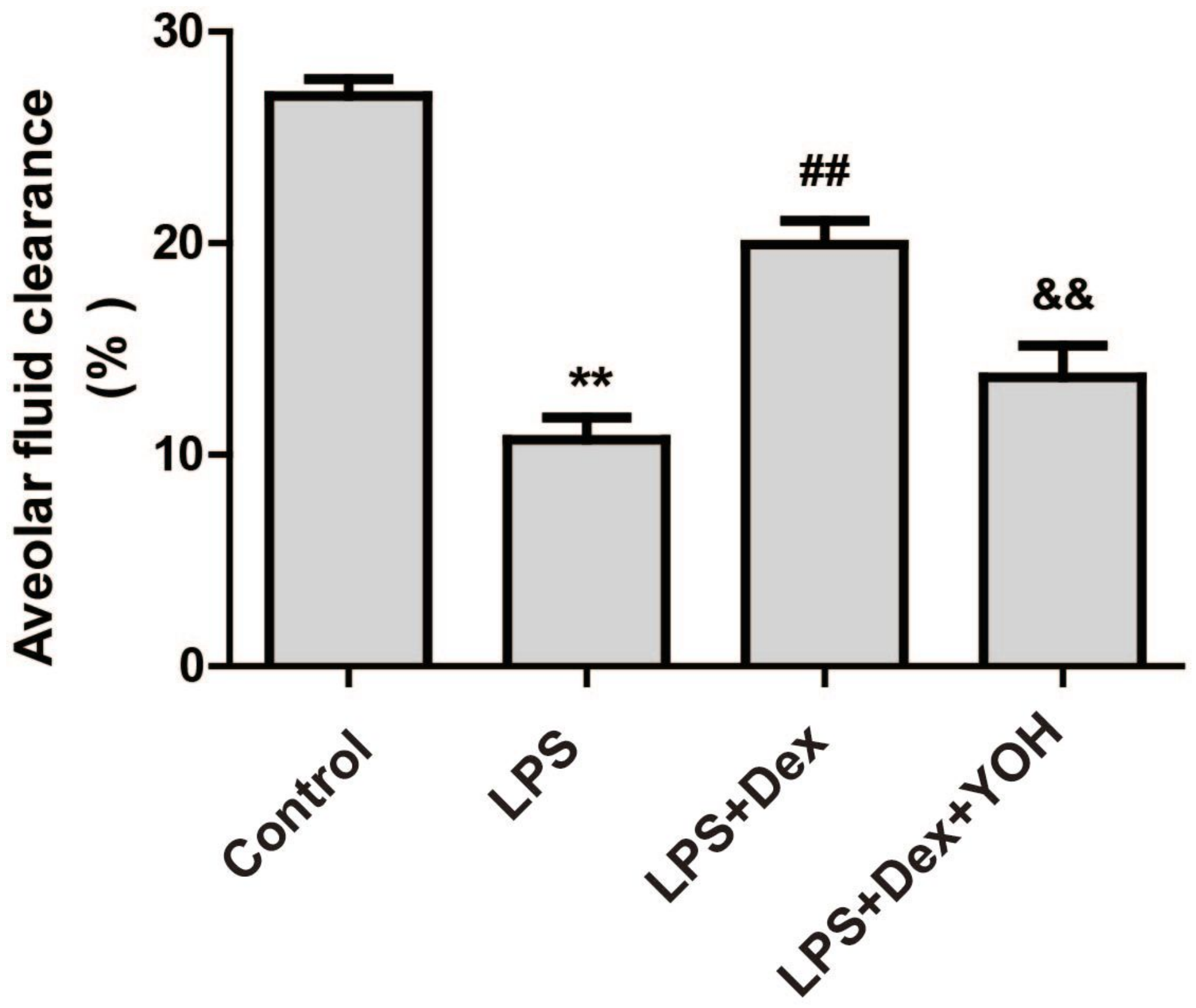

Figure 2

Effect of Dex on alveolar fluid clearance(AFC) in LPS-induced ALI in rats. All data are expressed as mean \pm standard deviation $(n=6)$. ${ }^{\star *} P<0.01$ vs. control group; \#\#P<0.01 vs. LPS group; $\& P<0.05$ vs. LPS+Dex group. 
a
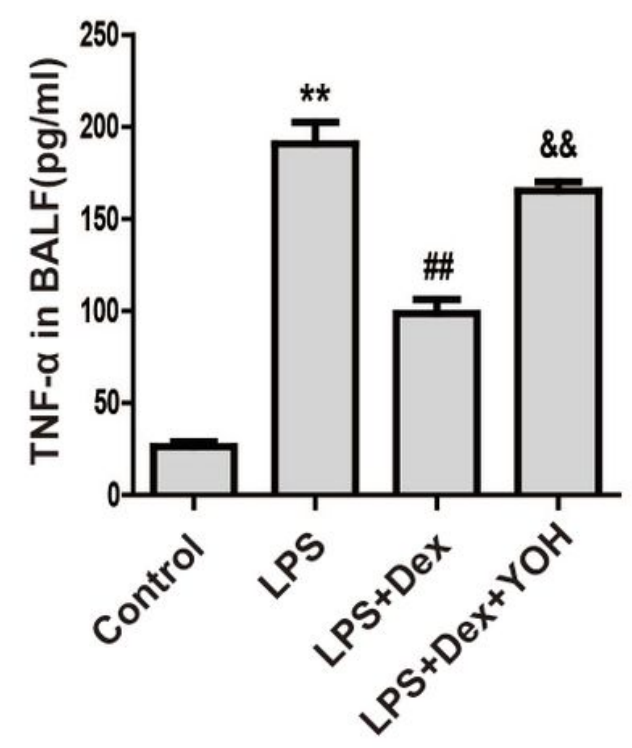

d

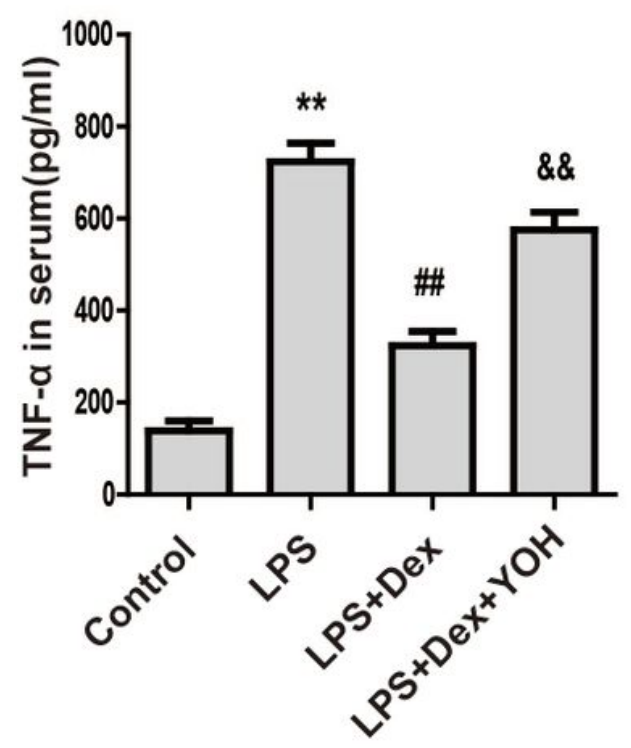

b

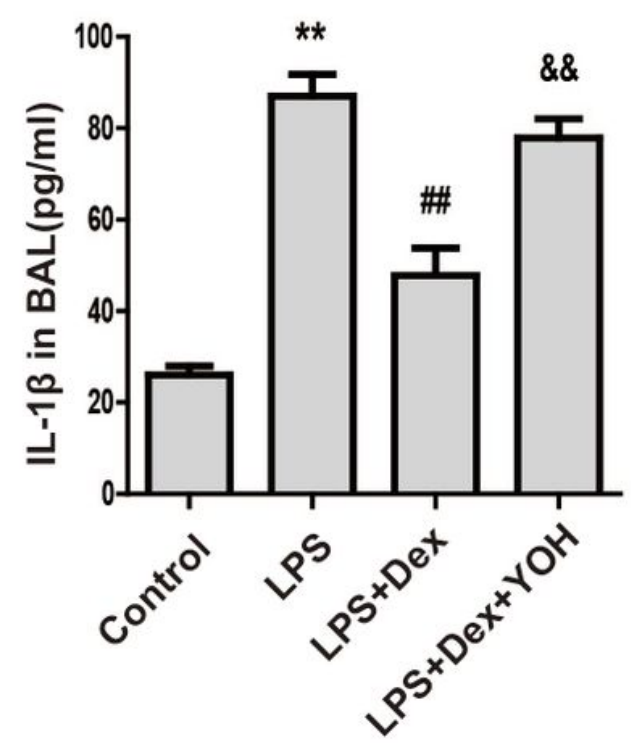

e

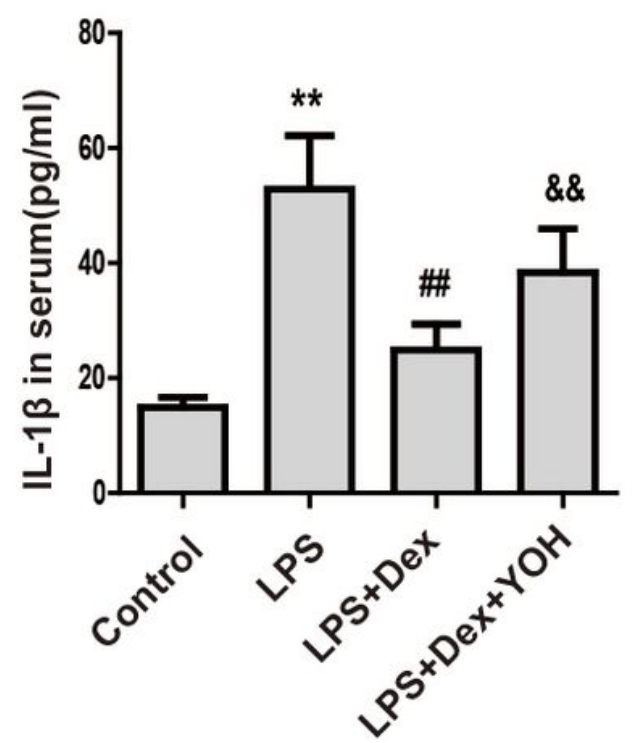

C
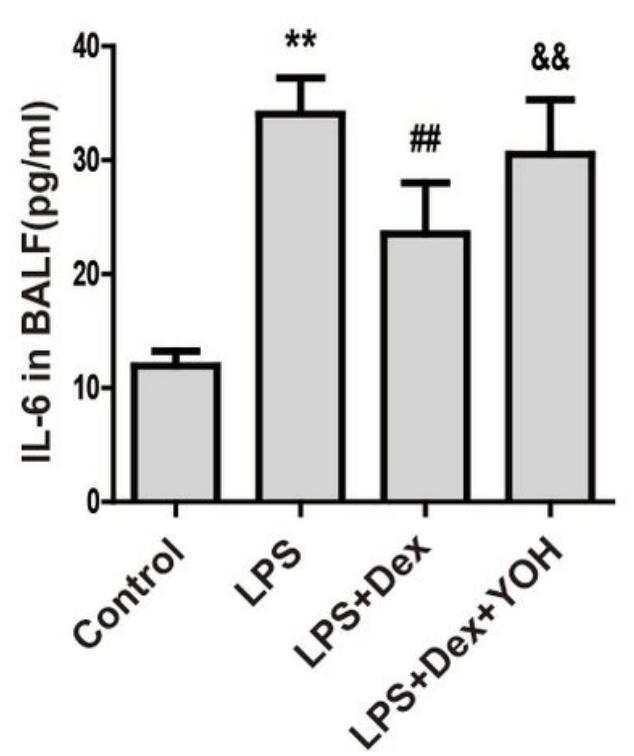

$\mathbf{f}$

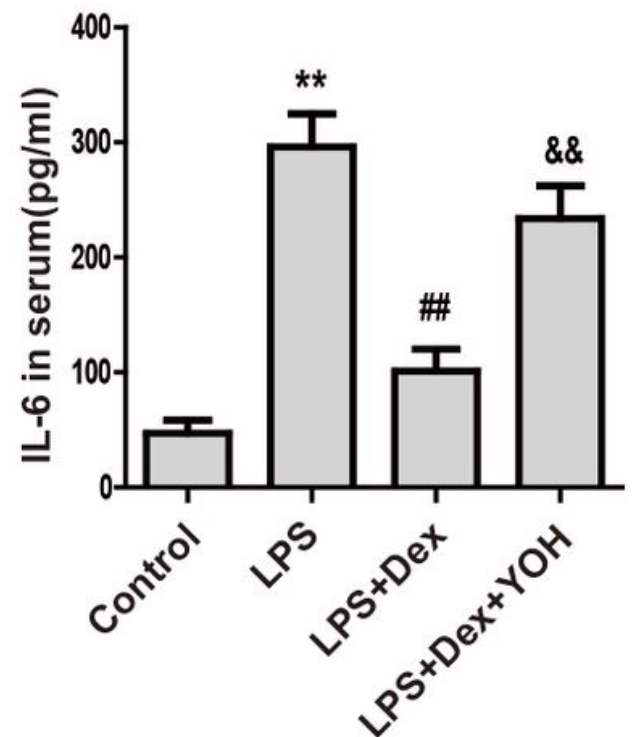

Figure 3

Dex reduces inflammatory response in LPS-induced ALI in rats. Represents the levels of TNF-a(a) , IL$1 \beta(b), I L-6(c)$ in BALF and the levels of TNF- $a(d), I L-1 \beta(e), I L-6(f)$ in serum. All data are expressed as mean \pm standard deviation $(n=6)$. ${ }^{*} P<0.01$, vs. control group; \#\#P<0.01 vs. the LPS group; $\& \& P<0.01$ vs. the LPS+Dex group . 
a

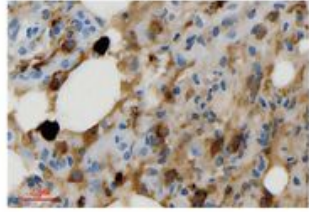

Control

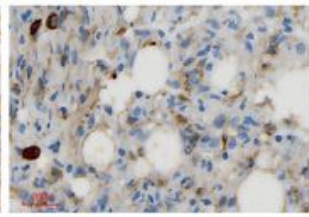

LPS

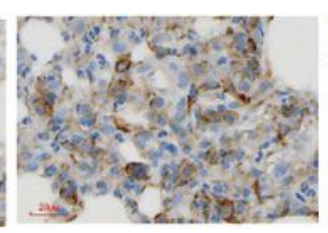

LPS+Dex

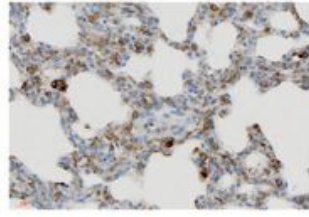

LPS+Dex+YOH

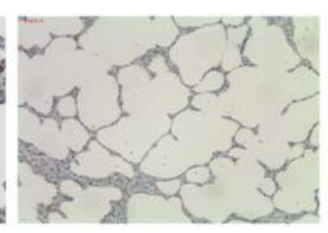

Negative control

b

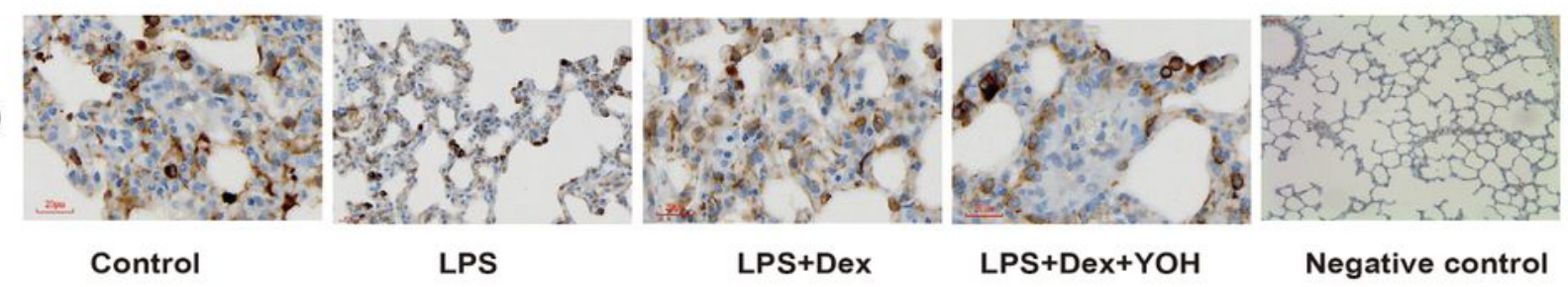

c

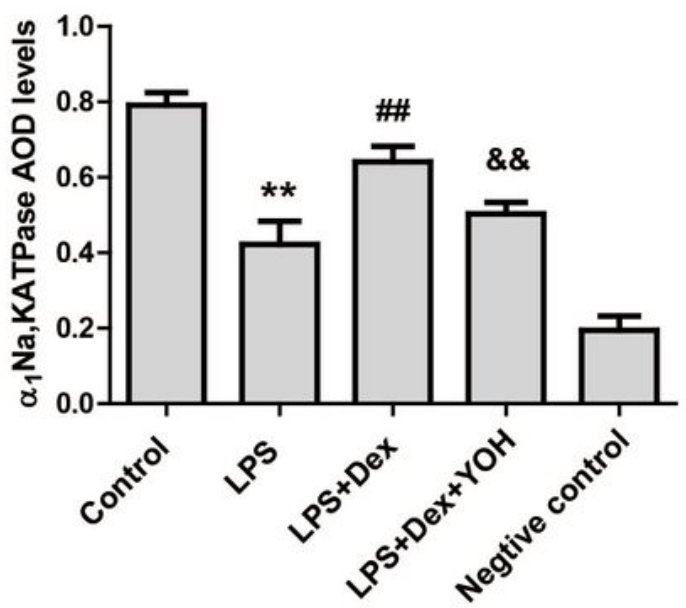

e
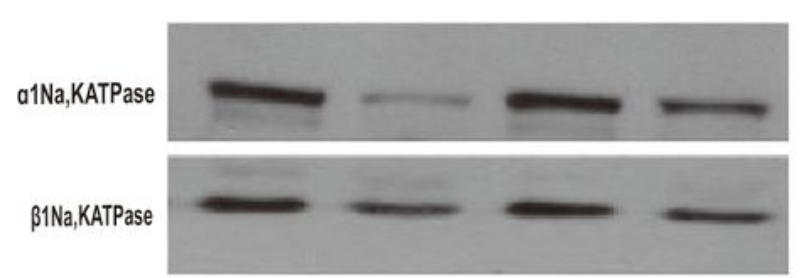

$\beta$-actin
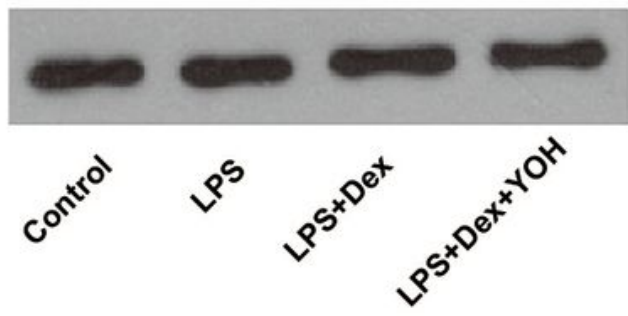

d
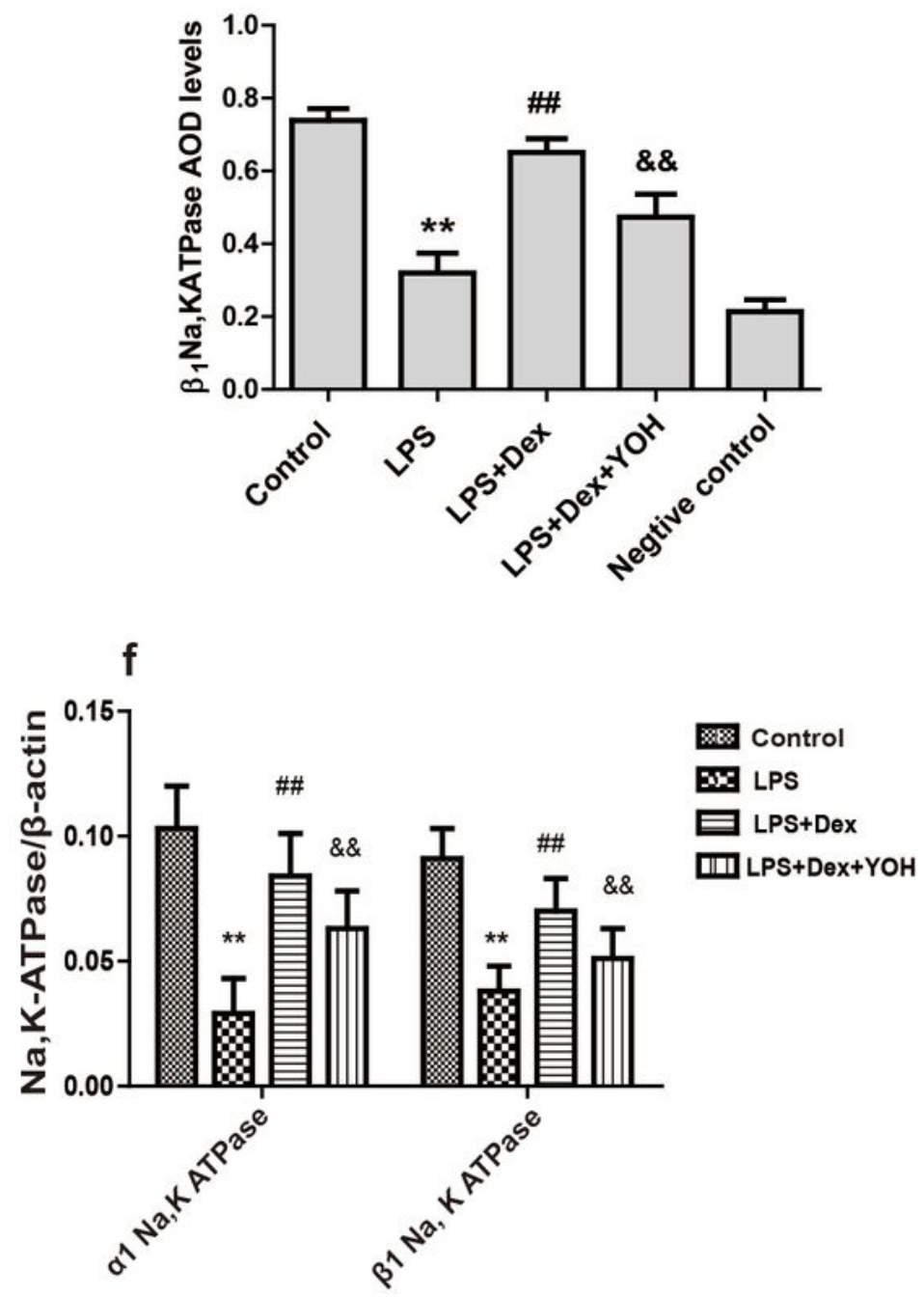

Figure 4

Effect of Dex on Na,K-ATPase of the lung tissues in LPS-induced ALI in rats. Represents the expression of a1 Na,K-ATPase(a) and $\beta 1 \mathrm{Na}, \mathrm{K}-\mathrm{ATPa}$ e(b) assesed by immunoh- istochemistry ; Represents densitometric quantification of the level of a1 Na,K-ATPase (c) and $\beta 1 \mathrm{Na}, \mathrm{K}$-ATPase (d). Represents the expression of a1 Na,K-ATPase and $\beta 1 \mathrm{Na}, \mathrm{K}-\mathrm{ATPa} e(\mathrm{e})$ assesed by western blotting; Represents densitometric quantification of the level of $\mathrm{a} 1 \mathrm{Na}, \mathrm{K}-\mathrm{ATPase}$ and $\beta 1 \mathrm{Na}$,K-ATPase (f). All data are 
expressed as mean \pm standard deviation $(n=6) .{ }^{*} P<0.01$ vs. control group; $\# \# P<0.01$ vs. LPS group; $\& \& P<0.01$ vs. LPS+Dex group.

a
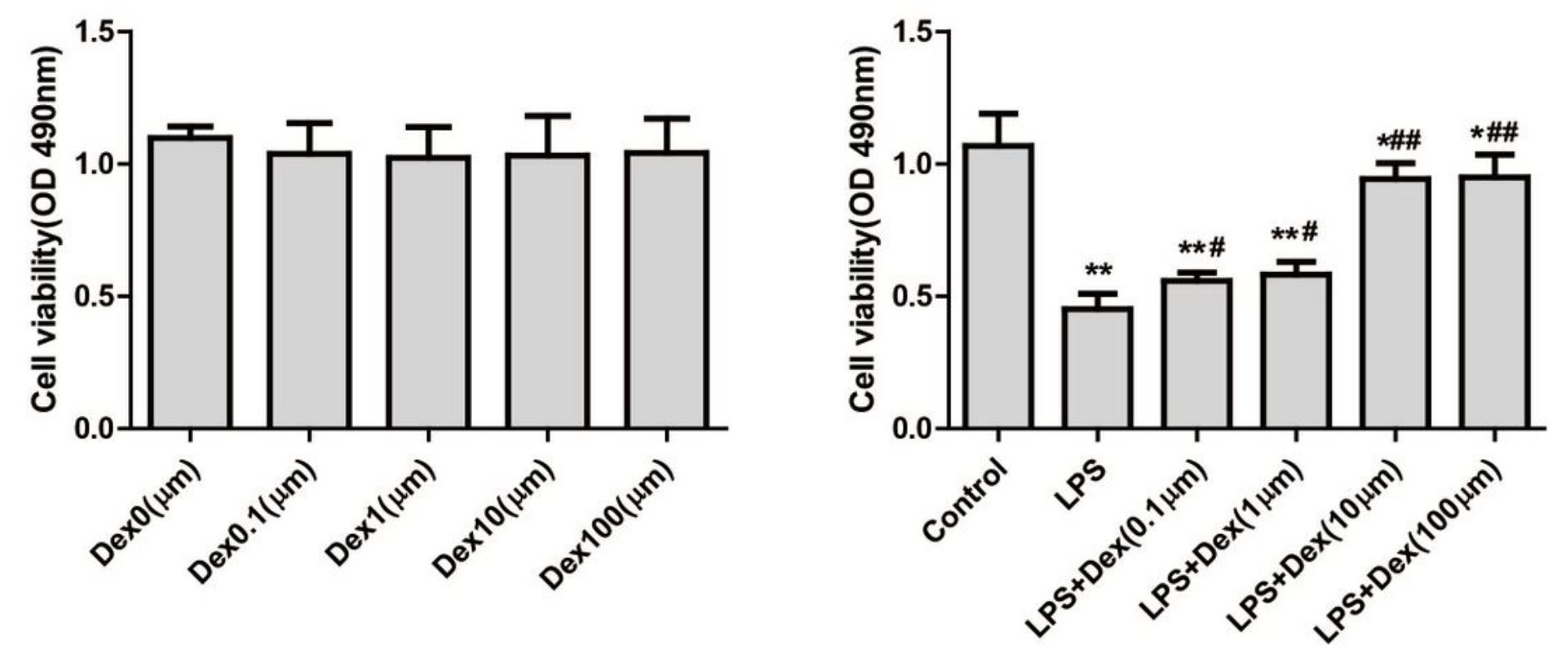

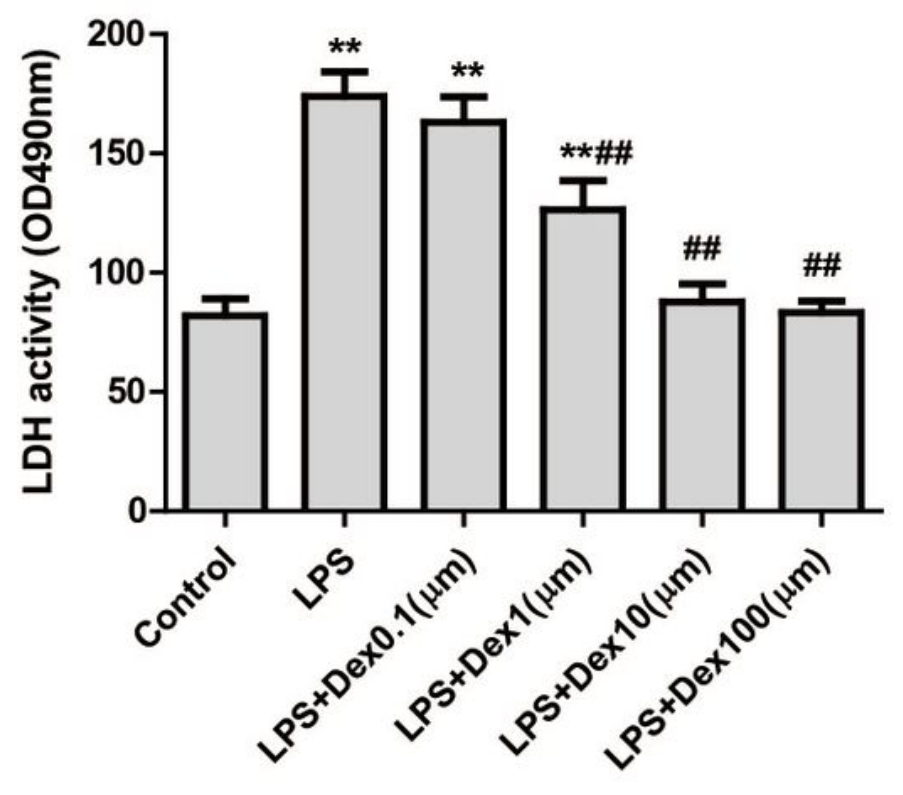

Figure 5

Effect of Dex on cell viability and LDH activity in LPS-stimulated A549 cells. Effects of different concentrations of Dex on cell viability(a); Effects of different concentrations of Dex on cell viability(b) 
and LDH activity(c) in A549 cells treated with LPS for 12 hours. All data are expressed as mean \pm standard deviation. ${ }^{*} \mathrm{P}<0.05$ or ${ }^{*} \mathrm{P}<0.01$ vs. control group; $\# \mathrm{P}<0.05$ or $\# \# \mathrm{P}<0.01$ vs. LPS group.

a

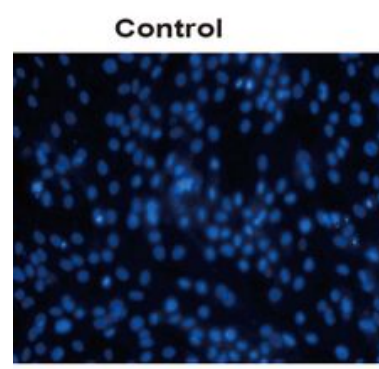

LPS+Dex

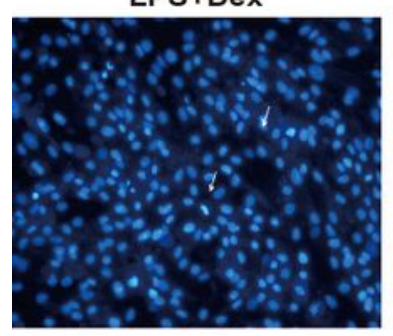

C

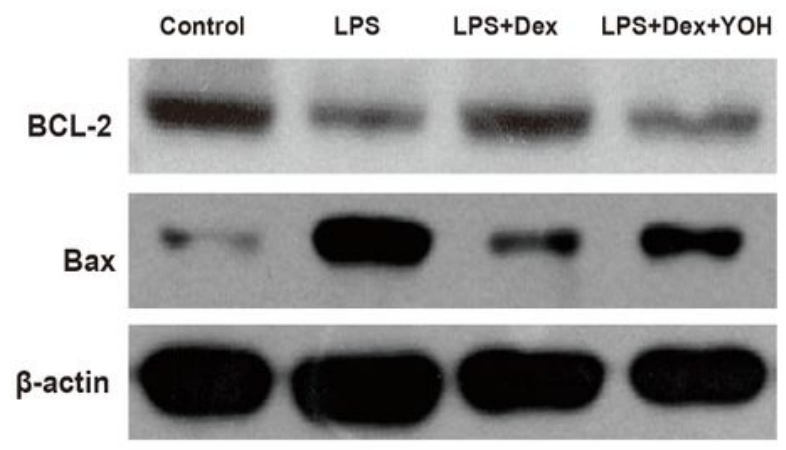

e

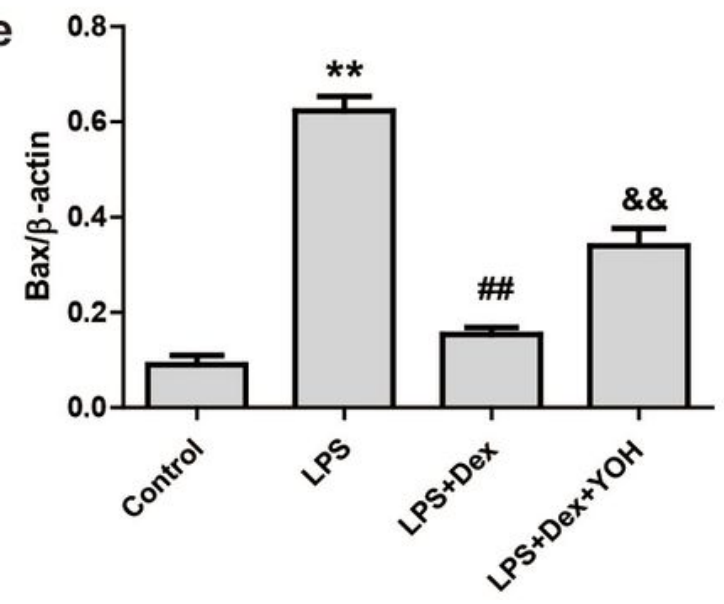

b

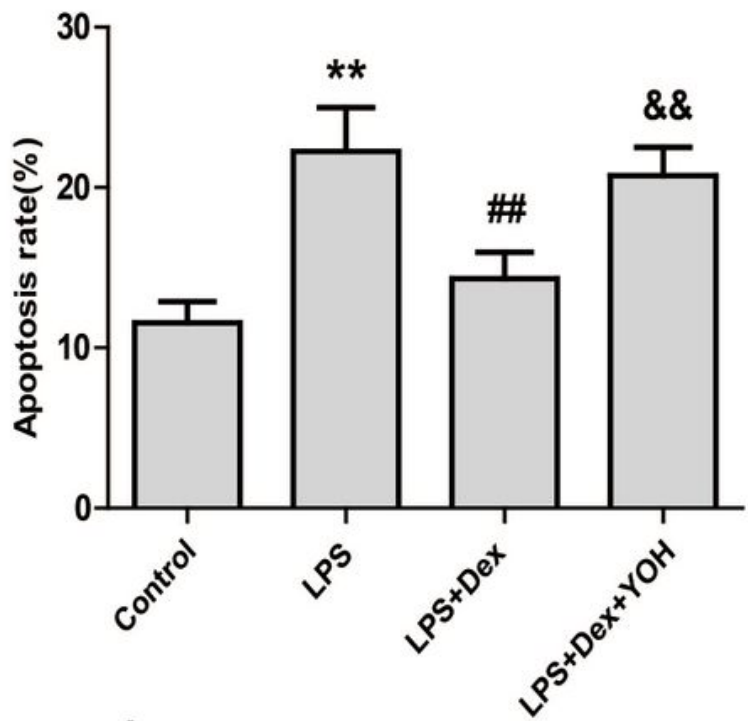

d

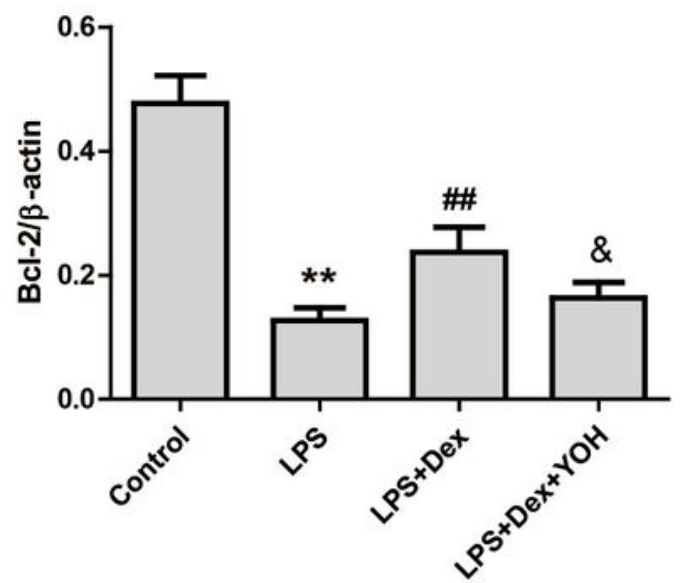

Figure 6

Dex inhibits LPS-induced apopotosis of A549 cells. Hoechst 33258 staining in A549 cells(a); Cell apoptosis rate(b); The expression of Bcl-2 and Bax in A549 cells(c) ; Densitometric quantification of the 
level of $\mathrm{Bcl}-2(\mathrm{~d})$ and $\mathrm{Bax}(\mathrm{e})$. All data are expressed as mean \pm standard deviation . ${ }^{\star \star} \mathrm{P}<0.01 \mathrm{vs}$. Control group; \#\#P<0.01 vs. LPS group; \&P<0.05 or \&\&P<0.01 vs. LPS+Dex group.

a

b

a1Na,K-ATPase

B1Na,K-ATPase

$\beta$-actin
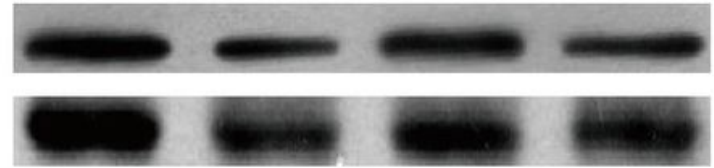

B-actin<smiles>[CH][Co]</smiles><smiles></smiles>
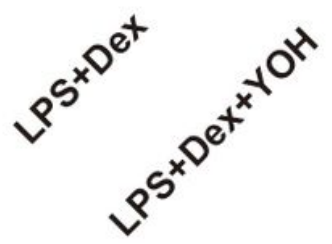

C
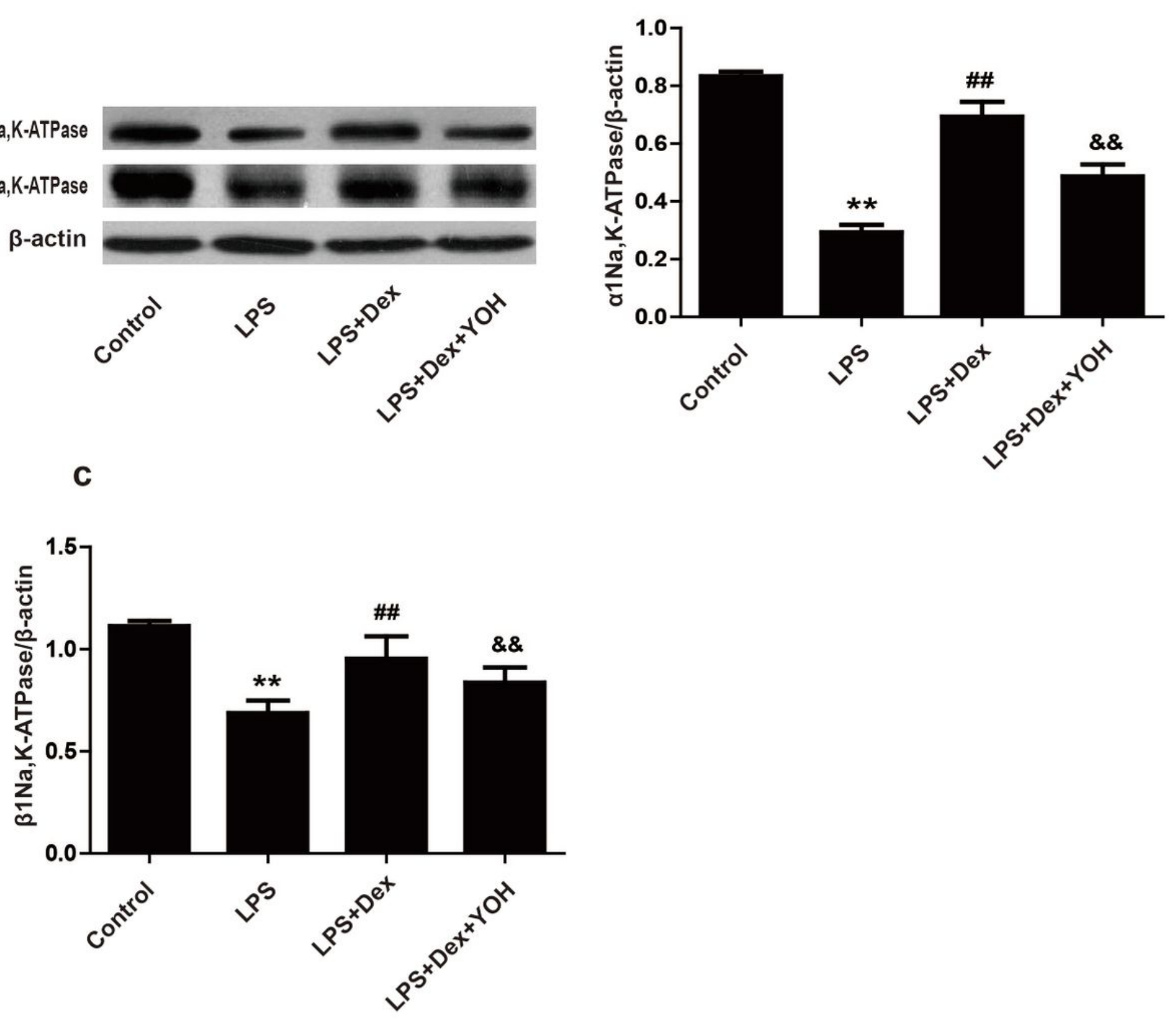

Figure 7

Effect of Dex on Na,K-ATPase in LPS-stimulated A549 cells. Representative western blotting results(a) and quantitative analysis of a1 Na,K-ATPase (b) and $\beta 1 \mathrm{Na}, \mathrm{K}-\mathrm{ATPase}(\mathrm{c})$ in A549 cells. All data are expressed as mean \pm standard deviation . ${ }^{\star *} \mathrm{P}<0.01$ vs. Control group; $\# \# \mathrm{P}<0.01$ vs. LPS group; \&\&P<0.01 vs. LPS+Dex group. 
a
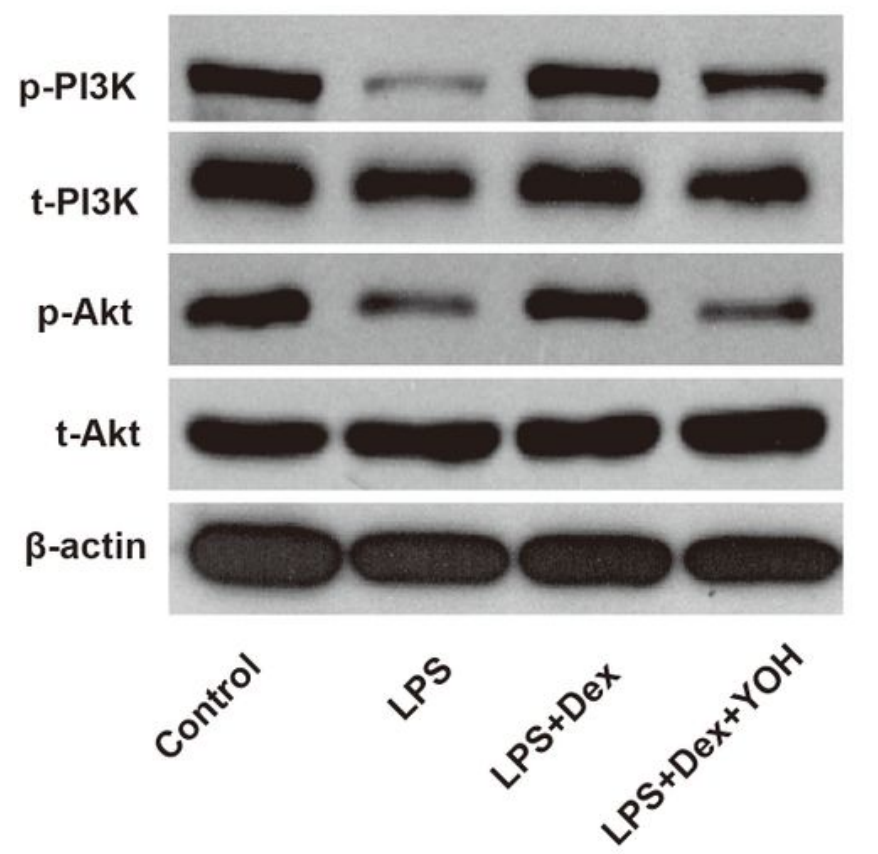

C

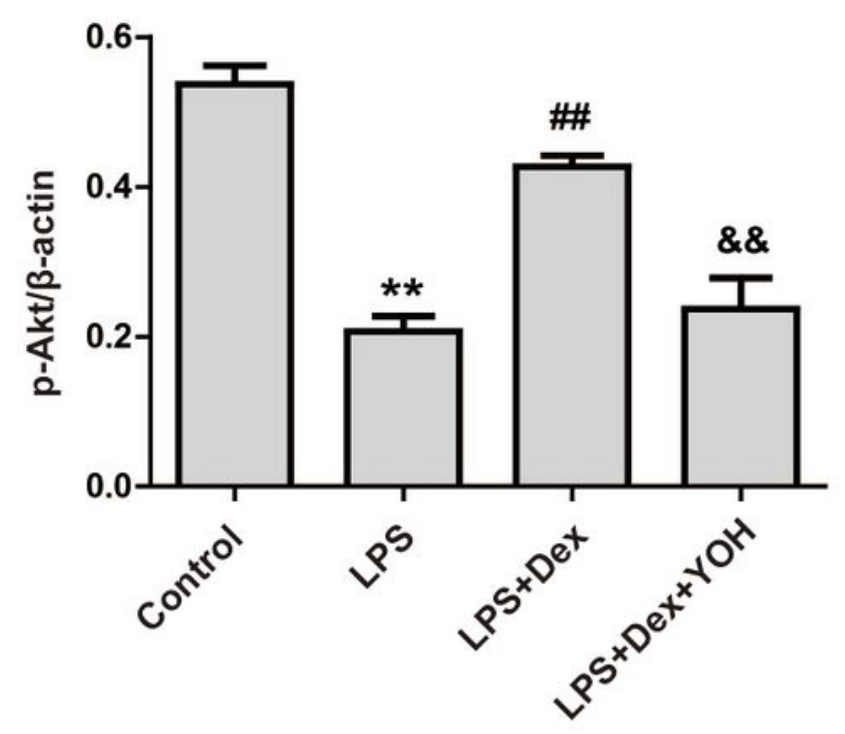

b

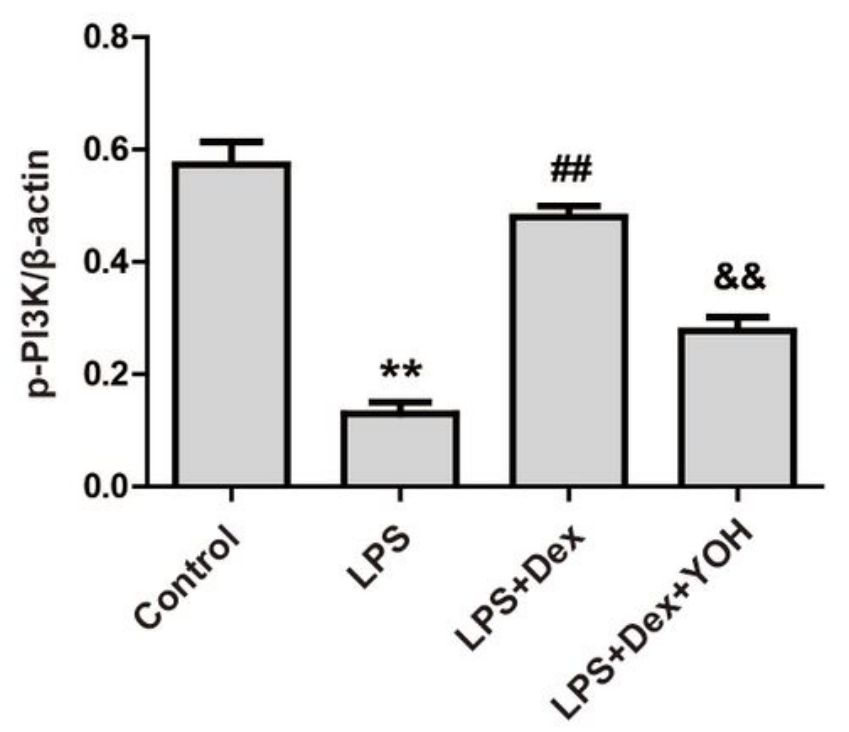

\section{Figure 8}

Effect of Dex on PI3K and Akt in LPS-induced ALI in rats. Representative western blotting results(a) and quantitative analysis of p-PI3K (b) and p-Akt(c) in lung tissues. All data are expressed as mean \pm standard deviation . ${ }^{\star \star} P<0.01$ vs. Control group; \#\#P<0.01 vs. LPS group; $\& \& P<0.01$ vs. LPS+Dex group. 
a

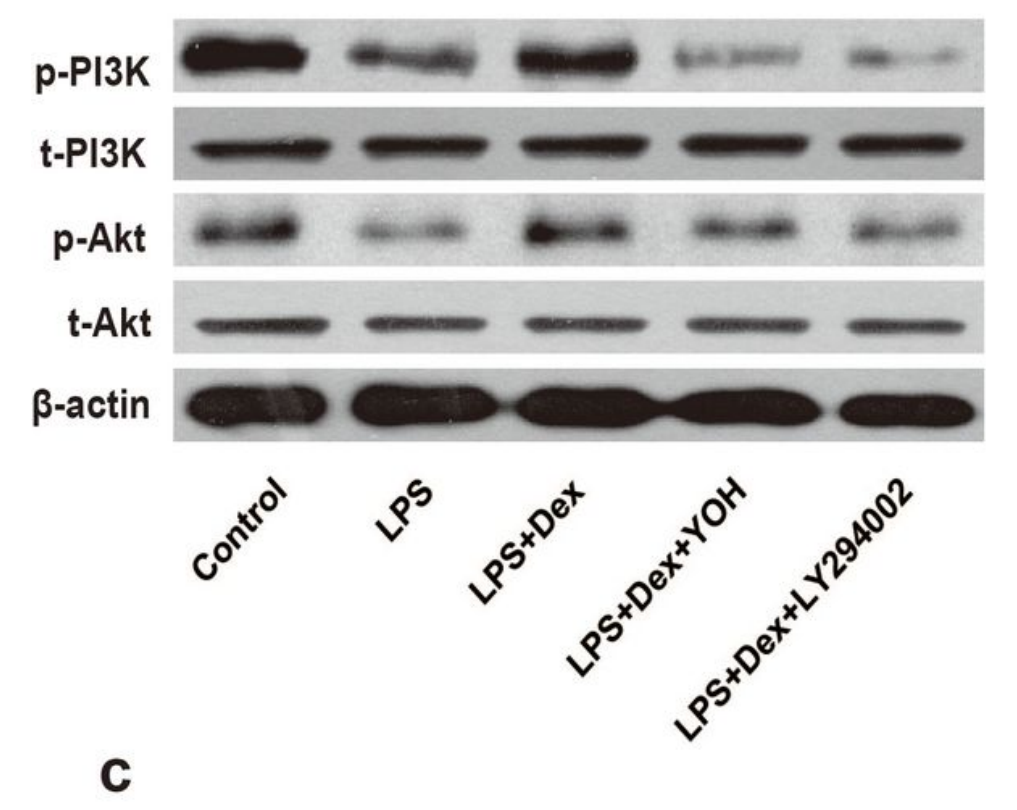

b

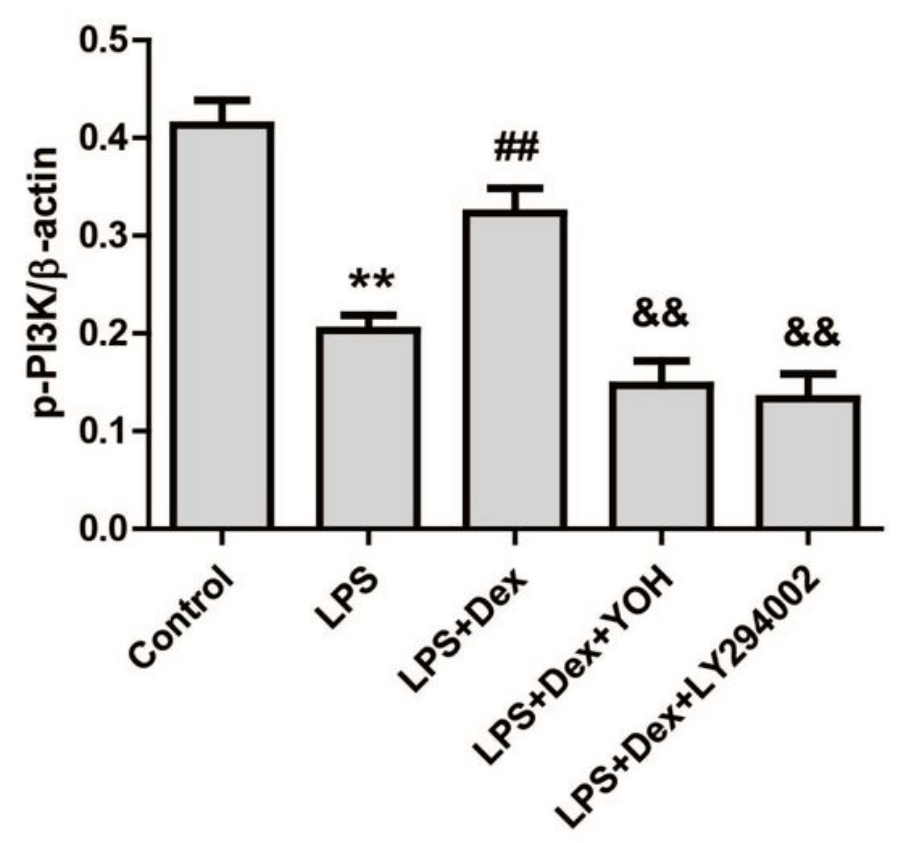

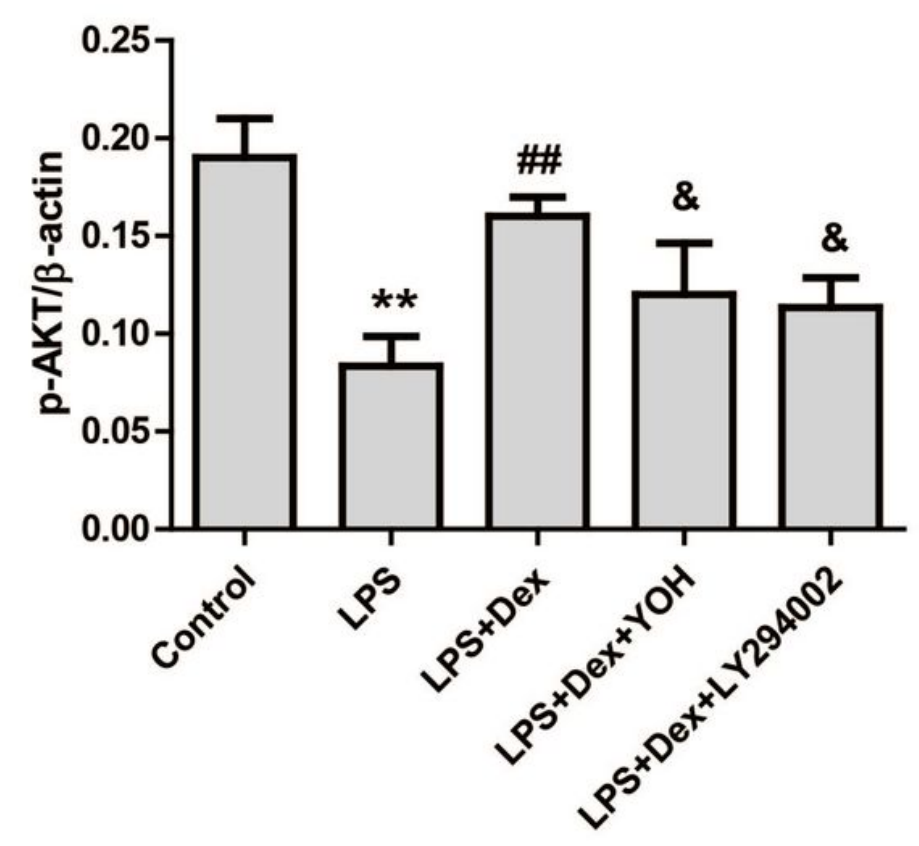

Figure 9

Effect of Dex on PI3K and Akt in LPS-stimulated A549 cells. Representative western blotting results(a) and quantitative analysis of p-PI3K (b) and p-Akt (c) in A549 cells. All data are expressed as mean \pm standard deviation . ${ }^{* \star P}<<0.01$ vs. Control group; $\# \# P<0.01$ vs. LPS group; $\& P<0.05$ or $\& \& P<0.01$ vs. LPS+Dex group. 